\title{
Speculative Hyperinflations: When Can We Rule Them Out?
}

\author{
Oscar J. Arce* \\ (Bank of Spain)
}

April 2006

First version: October 2004

\begin{abstract}
Motivated by a strong degree of hysteresis in the stock of monetization observed after the end of hyperinflations, I provide a cash-and-credit model in which the use of money exhibits some persistence because individuals can establish long-lasting credit relationships. This feature helps to account for the main stylized facts of extreme hyperinflations and reconcile some conflicting views on their causes, development and end without departing from rational expectations. Unlike the existing literature, I show that when hysteresis is possible, an orthodox fiscal-monetary reform that successfully stops a speculative hyperinflation may not be sufficient to prevent it.
\end{abstract}

Keywords: Hyperinflation; Fiscal-Monetary Reform; Multiple Equilibria; Hysteresis

JEL classification: E31; E41; E63

\footnotetext{
${ }^{*}$ I wish to thank Charles Goodhart, Albert Marcet, Kaushik Mitra and participants at several seminars at the London School of Economics for their helpful comments on various versions of this work. I am particularly indebted to Nobuhiro Kiyotaki for his valuable advice and suggestions. All errors are mine.

Disclaimer: The views expressed herein are those of the author and not necessarily those of the Bank of Spain.

Author's address: Research Department, Bank of Spain. Calle Alcalá 48. (28014) Madrid (Spain). Phone: +34 913386061. Fax: +34 91 3385678. e-mail: o.arce@bde.es
} 


\section{Introduction}

In this paper I provide a theoretical explanation for the main stylized facts observed during hyperinflationary processes as those experienced by some European, Latin-American and transition countries in the 1920 's, 80's and 90's, respectively. These episodes often display a common set of facts, yet much of the previous literature has followed a partial approach concentrating only on a reduced number of stylized features, as stressed by Bental and Eckstein (1990) and, more recently, by Marcet and Nicolini (2003). Indeed, some of the most influential partial explanations, when combined together, yield a picture that does not resemble what we actually observe in real economies. A central contribution aimed here is to present a simple rational-expectations general equilibrium model that potentially accommodates three of the most influential partial approaches -the fiscal root, the bubble explanation and the orthodox reform(described below), making them consistent with each other and with the empirical facts.

First, weak fiscal conditions that force the government to finance part of its expenses via money injections (seigniorage) are usually thought to be an important factor behind hyperinflations (the fiscal root). On the one hand, explosive hyperinflations often take place in countries in which seigniorage is relatively high and, on the other, a drastic reduction in this source of funding is observed after every successful stabilization. For instance, regarding the fiscal stance of some European countries in the 1920's, Sargent (1986; p. 45) observes that "the governments of these countries (Hungary, Austria, Poland, and Germany) resorted to the printing of new unbacked money to finance government deficits. This was done on such a scale that it led to a depreciation of the currencies of spectacular proportions." (parentheses added). Although the exact intertemporal mechanisms linking inflation and seigniorage are likely to be rather complex, as shown by Sargent and Wallace (1981), the common proposition that associates high inflation to a high degree of fiscal-dominance in the implementation of monetary polices remains basically uncontested. ${ }^{1}$

Second, for some students of these episodes, the lack of strong correlation between inflation and seigniorage over the course of some hyperinflations suggests that they may well be driven just by expectations that, in equilibrium, are self-confirmed (the bubble explanation). This approach has received a formal treatment under the rational expectations paradigm, among others, by Sargent and Wallace (1987), and Bruno and Fischer (1990). In both cases, it is assumed a demand for real balances à la Cagan (1956), which implies the existence of a hump-shaped inflation-tax Laffer curve with two stationary inflation rates (one "low" and one "high") associated with a unique volume of seigniorage, and a hyperinflation is interpreted as the economy moving from the vicinity of the low inflation rate to the high one. According to this view seigniorage is not the sole explanation for high inflation, instead, private expectations are thought to be the prime cause. However, in explaining the occurrence of a hyperinflation as a bubble equilibrium along a standard Laffer curve, the degree of fiscal pressure does not play any

\footnotetext{
${ }^{1}$ Although there are some divergent views on this issue. For example, Loyo (2001) provides an explanation for the hyperinflationary bursts in Brazil in the 1980's and 90's using a cash-less model in which the volume of seigniorage is negligible.
} 
significant role. More on the contrary, as the economy moves towards the decreasing arm of the Laffer curve, higher levels of seigniorage will result in lower inflation rates. Still, such a possibility has also attracted much attention in the empirical literature. ${ }^{2}$ For example, Imrohoroglu (1993), provides empirical support for Sargent and Wallace's multiple-equilibria model using data from the German hyperinflation.

Third, for a wide class of rational-expectations economic models, including those in the tradition of Cagan mentioned above, Obstfeld and Rogoff (1983) have shown that the prospect of a fiscal-monetary reform aimed at stabilizing the real value of the currency through a restrictive monetary policy (the orthodox reform) is itself a sufficient condition to preclude a speculative hyperinflation, thus making it difficult to reconcile the idea of a hyperinflation as a rational-bubble equilibrium. ${ }^{3}$ Moreover, once the possibility of a reform is introduced in a model with rational expectations and a Cagan demand for money what one learns is that higher seigniorage is uniformly associated with more severe disinflationary processes. Yet, if anything is unambiguously true about hyperinflations is that they are always stopped. There is little doubt either that this is the result of the government's determination to reform the fiscalmonetary mix, i.e. to implement "deliberate and drastic fiscal and monetary measures taken to end the hyperinflations" (Sargent 1986; p. 44).

Clearly, when combined together, these three partial views do not fit each other. Yet, there have been few attempts to provide a general explanation of hyperinflations, including their causes, dynamics and end. To the best of my knowledge, most of them consider models in which the preventive role of an eventual reform, as the one outlined above, is not explicitly considered. ${ }^{4}$ Marcet and Nicolini (2003) consider a baseline model similar to the one studied by Sargent and Wallace (1987) but assume that individuals follow a backward-looking rule for forming expectations (quasi-rational learning). They show that under some conditions on the learning rule the model is able to match most of the stylized facts. Sargent et al. (2005) have recently provided econometric support for the ability of Marcet and Nicolini's model to explain the time series of inflation using data from several Latin-American countries. However, as in this class of models individuals do not internalize the possibility of a future change in the policyregime when forming their expectations, the prospect of a reform is itself irrelevant for the dynamics of the model.

Using the same Cagan-model, Kiguel (1989) argues that a volume of seigniorage above the maximum one in a steady-state inflation-tax Laffer curve will unchain an explosive hyperinflation if the money market does not clear instantaneously. ${ }^{5}$ Although he explicitly considers the implementation of a reform as a device to stop the hyperinflation, the expectation of a reform does not have any effect on individuals

\footnotetext{
${ }^{2}$ Since, at least, the influential work of Flood and Garber (1980), a large number of authors have tried to detect bubblecomponents using data from hyperinflationary economies. The results are mixed and the comparison across different studies is not always easy, as there is a wide heterogeneity in the specification of the money demand function, the money supply process, etc. For some recent contributions on this area see e.g. Blackburn and Sola (1996), and Hooker (2000), and the references therein.

${ }^{3}$ See also Nicolini (1996) for a similar argument.

${ }^{4}$ Drazen and Helpman (1990) provide an exception since they explicitly model the effects of an anticipated change of regime. However, in order for their model to generate a hyperinflationary path, an upward seigniorage-path is required. Yet, as discussed below, this is not a common feature in hyperinflationary episodes.

${ }^{5}$ Romer (2001) presents a simplified version of this model.
} 
decisions before its implementation either.

The two models just mentioned provide a rationale for the fiscal root view, however at the cost of neglecting the government's policy path followed beyond the current date. A different view is taken by Bental and Eckstein (1990) and Paal (2000), since in these models the anticipation of a reform is thought to be the cause of the hyperinflation. Bental and Eckstein explain the relatively low level of monetization (i.e. the stock of real balances) observed for a long time after the end of a hyperinflation as a consequence of a negative wealth effect arising from the increase in income-taxes accompanying a fiscalmonetary reform. Then they interpret a hyperinflation as the economy moving from a scenario of a high demand for real money to a stationary one in which the stock of real balances remains low, in line with a lower level of private wealth. Paal (2000), referring to the hyperinflationary episode in Hungary in the 1940 's, argues that a reform based on the stabilization of the inflation rate without directly controlling for a monetary aggregate may actually leave the economy prone to purely expectational-driven equilibria, some of them hyperinflationary, some others exhibiting a pronounced disinflation. Anticipation of such a change in the monetary rule rather than a weak government's fiscal condition could have been, according to this model, the true cause of the Hungarian hyperinflation. ${ }^{6}$

The approach followed in the present paper may be seen as complementary to the general explanations listed above, for it shares some basic features with them, yet takes a different route. I do not impose ex ante any special assumption on the current effects of a future fiscal-monetary reform. Rather, I am concerned with the conditions under which the prospect of an eventual reform exerts a preventive effect. In this sense, I build up a framework within which the effectiveness of a reform to prevent a hyperinflation arises as an endogenous outcome. To this aim, I formulate a rational-expectations model whose cornerstone is its potential ability to display one of the most recurrent empirical facts in hyperinflationary economies, namely, a post-reform hysteresis-effect in the demand for (national currency) real balances. Referring to this phenomenon, Calvo and Végh (1992; p. 11) note that "high inflation forces a gradual development of new financial instruments [...] Creating new financial products is costly and requires a learning process. Once this investment has taken place, the public will continue using these new financial instruments even if inflation falls". ${ }^{7}$

Along this line of reasoning, the model developed later features a gradual development of a nonmonetary financial instrument whose initial adoption is costly but can be used even if inflation falls.

\footnotetext{
${ }^{6}$ This argument resembles the bubble explanation above, however with an important difference. For instance, in Sargent and Wallace (1987), the government directly sets a target for seigniorage at every period. Paal, on the contrary assumes that at the time of the reform the government, by committing to a non-contingent inflation target, leaves both the volume of seigniorage and the supply of money indeterminate, very much like what we would observe when a central bank switches from a rule based on the control of a monetary aggregate to one based on the control of the short-term interest rate, as described in Sargent and Wallace (1975). Then, she associates the occurrence of an explosive hyperinflation with a self-confirmed high volume of seigniorage at the precise time of the reform.

${ }^{7}$ A similar observation can be found in Dornbusch et al. (1990; p. 23-24): "The distinction between movements along the real money demand schedule and shifts in real money demand helps explain the actual dynamics of real balances during an inflation. The distinction may also explain why there are hysteresis effects. Once a new financial product is in use, it will continue to be used even if inflation declines. [...] Financial institutions are not ready-made to accommodate the flight from money. In the short run, households may hold more real balances than they will after alternative vehicles become available or better known. In practice, this will look like adjustment lags, but it also reflects the adjustments of financial institutions to the increased inflation."
} 
There are several theoretical models in the previous literature designed to account for some of these facts. For example, Ireland (1995), Sachs (1995) and Uribe (1997) all provide examples of economies in which a form of financial innovation exhibits long-lasting effects. However, to my knowledge, no model of financial innovation or currency substitution has been previously exploited to account for the stylized effects we are after, including an explosive inflation-path and a sudden change of policy-regime. Thus, a methodological contribution of the paper consists in bringing together these two strands of the literature, a natural step after recognizing that the incentives to invest in financial products not directly subject to the inflation-tax are probably highest when inflation reaches several-digits values, and that the most pronounced episodes of rapid demonetization and slow remonetization are observed during hyperinflationary episodes.

Specifically, I model the demand for monetary balances as a version of Ireland (1995) cash- and creditgoods environment. Households may acquire their desired consumption basket using either cash or credit. However, credit requires the prior investment of some valuable resources for building up long-lasting producer-shopper relationships which can be exploited for some time to avoid the inflationary cost of carrying cash. ${ }^{8}$ On the side of monetary supply, I follow the standard assumption of a government aiming at collecting an exogenous and constant amount of seigniorage over a fiscal-dominance regime which is possibly reversed at some future date by the implementation of a monetary-fiscal reform conducive to a low-inflation monetary-dominance regime. ${ }^{9}$ Private agents are assumed to be aware of the eventual change of regime.

This simple formal set up provides a natural interpretation of the links among the fiscal roots of hyperinflations, their dynamics and termination and the relative role of expectations and fundamentals. In particular, provided some mild conditions hold, the model exhibits up to three general classes of potential equilibria over the fiscal-dominance regime. First, a unique low-inflation equilibrium that arises when the public expects a "responsible" government policy in the form of a combination of a low level of deficit-monetization and an early and/or restrictive reform. Second, a unique high- and increasinginflation path that obtains in the opposite policy scenario (i.e. high seigniorage and late/insufficiently restrictive reform). Third, for some structural parameters and government policy choices lying in between the two previous extreme cases, the model displays multiple equilibria, some of them hyperinflationary, whose realization hinges crucially on private expectations and, thus, speculative in nature.

Overall the main insights of the paper are two. First, on the theory side, the paper argues that the practical relevance of the arguments put forward by Obstfeld and Rogoff (1983), concerning the

\footnotetext{
${ }^{8}$ I stick at the cash- versus credit-transactions parable for simplicity and without loss of generality. The basic arguments can be extended to alternative forms of carrying out transactions that do not rely on the use of domestic money (e.g. dollarization, barter, etc.)

${ }^{9}$ As further clarified later, this is the standard assumption followed in the "general" approaches commented above, in which no attempt to explain the government behavior (beyond that of a mechanic monetization of a portion of the deficit) is made. In another branch of the literature (see e.g. Albanesi 2006 and the references therein) the degree of fiscal pressure on monetary policy is modelled explicitly as the outcome of a game between economic authorities and/or groups of interest. Within this political-economy branch, Mondino et al. (1996) provide a model with some similarities to the one developed here, since they allow for a mechanism of financial innovation with log-lasting effects. Yet, the questions they pose and their methodology are different from the ones pursued here.
} 
effectiveness of a future reform to rule out a speculative hyperinflation, must be qualified in view of the empirical evidence, for the existence of hysteresis in real balances suggests that the sufficient condition for the validity of their arguments (i.e. the lack of causality running from past to future states along an equilibrium in which the prospect of a reform is internalized by the households) does not hold in real economies. Indeed, in an economy in which hysteresis is a true possibility, the conditions for an ex ante effective reform are likely to be much more complex than in the history-independent economy studied by those authors. As a result, speculative hyperinflations in this setting are possible equilibrium outcomes even under the threat of a future reform. This feature of the model allows us to reconcile the three influential views on hyperinflationary processes described above.

Second, the model offers some insights relevant for policy judgment. In particular, fiscal conditions are shown to play an important role, as stressed by Marcet and Nicolini (2003) and Sargent et al. (2005). However, using a genuine rational-expectations dynamic framework we learn that seigniorage over the fiscal-dominance regime, while important, does not contain all the relevant fiscal-information. For instance, the horizon over which that regime is implemented and the fiscal-monetary conditions prevailing after the reform are also likely to bear a direct effect on the conditions that determine whether a hyperinflation is a feasible outcome or not.

The rest of the paper is organized as follows. Section 2 describes the main empirical facts observed in a variety of hyperinflations. Section 3 contains the model. Section 4 discusses conditions under which expectations-driven hyperinflations are possible equilibrium outcomes under the assumption that the government commits to implement the reform at a pre-announced future date, and section 5 extends the analysis to the case of a state-contingent reform. Section 6 summarizes the main results of the paper.

\section{Empirical motivation: Stylized facts}

As pointed out by Marcet and Nicolini (2003) many hyperinflations, even if distant in time and/or geographical location, display a number of common facts. Below, I briefly describe the most recurrent facts.

- Hyperinflations usually occur in countries experiencing important fiscal imbalances, in the sense that the resources that the government is able to collect from regular taxes and borrowing from financial markets are on average significantly below the level of its expenditures, so that the resulting difference is funded by printing money. Fischer et al. (2002) report a strong positive relationship between seigniorage, deficits and inflation using annual observations corresponding to a sample of 24 high-inflation countries over the period 1960-1995. A similar overall picture can be found in Catão and Terrones (2005). Also, many country-specific studies also stress the role of seigniorage as a potential cause of hyperinflationary bursts. ${ }^{10}$

\footnotetext{
${ }^{10}$ See for instance (in italics the country under analysis) Sachs (1987; Bolivia), Eckstein and Leiderman (1992; Israel), Kiguel and Neumeyer (1995; Argentina), and Petrovic et al. (1999; Yusgoslavia).
} 

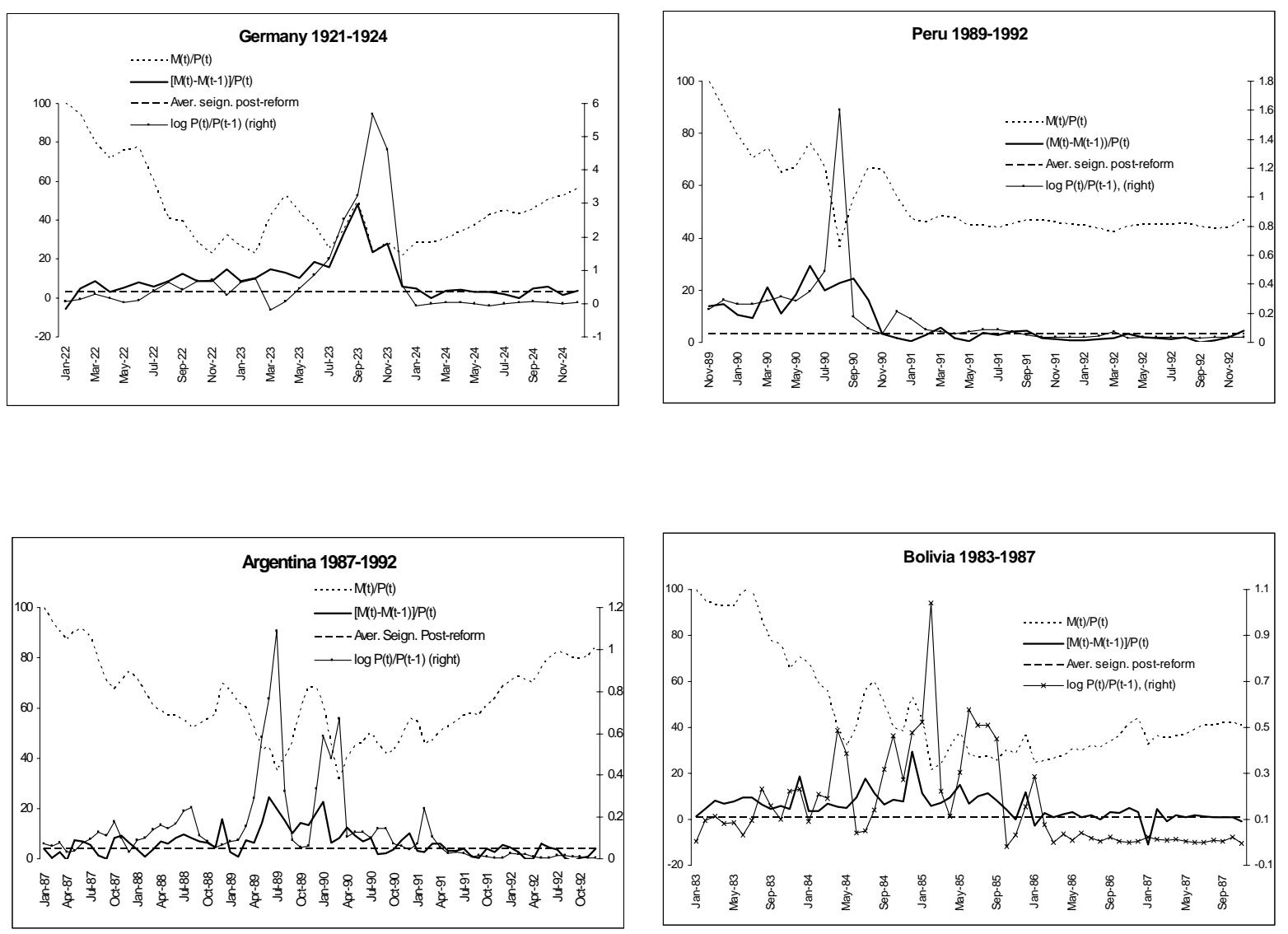

Left scale: real balances and seigniorage computed using base money $\left(\mathrm{M}_{0}\right)$ as percentage of the initial date value for real balances. Average seigniorage in the post-reform regime is computed as the simple mean of seigniorage for the following periods: Germany (Jan 1924 - Dec 1924), Argentina (Apr 1990 - Dec 1992), Bolivia (Mar 1986 - Nov 1987), Peru (Sep 1990 - Dec 1992). Right scale: natural log of gross inflation computed from wholesale prices (Germany) and CPI (Argentina, Bolivia and Peru).

Sources: Germany: Holtfrerich (1986) and Sargent (1986). Argentina: Boletín Estadístico, Banco Central de la República Argentina (several issues). Bolivia: Memoria, Banco Central de Bolivia (several issues). Perú: Boletín Mensual, Banco Central de Reserva del Perú (several issues).

Figure 1: Monetary base, seigniorage and inflation 
- When inflation reaches its highest values within the hyperinflationary episode there is a lack of strong contemporaneous correlation between seigniorage and inflation. Indeed, seigniorage may well decrease significantly while inflation still grows at increasing rates. ${ }^{11}$

- Stopping a hyperinflationary process usually involves a mix of fiscal and monetary reforms whose aim is to set limits to the ability of the government to monetize its deficit by e.g. cutting public expenditure, fixing the exchange rate to a foreign currency with a good reputation in terms of inflation, establishing legally independent central banks with limitations to the amount of funds let to the government, implementing rules to keep the growth of the money supply under limits (e.g. through currency boards), etc. ${ }^{12}$ The process of inflation-stabilization, from the peak of the inflation series to the post-reform low rate, takes a short period (a few months at most).

- The stock of real balances falls as inflation increases over the course of a hyperinflation and remains low but exhibiting an upward trend for a long period after the stabilization. In recent times, this observation is closely related to the phenomenon of dollarization, i.e. the quasi-permanent substitution of a foreign currency for the local one. For some recent empirical work on this question see e.g. Kamin and Ericsson (2003) and Reinhart et al. (2003). This hysteresis-effect is behind the well documented observation that, just after the stabilization, (nominal) money supply increases at moderate-high rates without causing noticeable inflationary pressure.

Figure 1 contains some evidence on several hyperinflationary episodes recorded in Germany, Argentina, Bolivia and Peru. These data generally confirm the standard facts above. In all cases, the rise in inflation goes parallel to the fall in real balances. The peaks in the inflation rate coincide with the lowest value of the stock of real money recorded for the entire period. At that point the stock of real balances falls bellow the $40 \%$ of its value a couple of years before. Although average seigniorage is clearly higher in the pre-reform period than after the collapse of the hyperinflationary path for the four countries, in some cases inflation reaches its highest value while seigniorage is decreasing (as in Germany 10:1923 and Bolivia 12:1984-2:1985) while in others seigniorage remains high and increasing (as in Argentina) or fairly constant (as in Peru). In all cases, after the stabilization, the volume of seigniorage was drastically cut down, inflation remained low and stable, and the stock of real balances exhibited a very slow recovery, thus confirming a strong hysteresis-effect.

\section{The model}

The model developed in this section is inspired in the cash-and-credit transactions economy studied by Ireland (1995), who extends Lucas and Stokey's (1987) framework to allow for persistent effects in the use of credit. Households are assumed to exchange their consumption endowments by using government-

\footnotetext{
${ }^{11}$ The absence of a marked trend in seigniorage during hyperinflationary periods has led many researchers to model this variable as a constant (or with a constant mean, in stochastic environments). This is the strategy followed by e.g. Bental and Eckstein (1990), Bruno and Fischer (1990), Kiguel (1989), Marcet and Nicolini (2003), Paal (2000), Sargent and Wallace (1987), and Sargent et al. (2005). The model presented here uses this simplifying assumption too.

${ }^{12}$ See, e.g. Bruno et al. (1991) for a comprehensive review of several inflation stabilization processes.
} 
provided money or interpersonal credit. The latter requires the existence of a credit-link between the intervening parts whose creation involves some initial fixed and irreversible cost. However an existing link can be used at not further cost at any subsequent date at which it remains operative. Transactions made using money do not carry over any explicit cost beyond that associated with inflation.

The main difference with respect to Ireland's model is intended to keep the subsequent dynamic analysis as simple as possible. ${ }^{13}$ In particular, I assume that the volume of investment in the credit technology in any period is bounded above, as the opportunities for investment arrive at a finite rate. This artifact allows me to focus on monetary regimes along which the government is able to extract an exogenously set amount of seigniorage over a non-trivial number of periods.

The households. Consider a discrete-time economy with $N(\geq 3)$ types of goods and $N$ types of households of population size $1 / N$ each. The household of type $j$ produces good $j$ and consumes good $j+1$ (except the one with type $N$, who consumes good 1). Each household consists of a continuum of members of unit mass. Half of the members within a household are producers, who can obtain their goods up to a given capacity, which is normalized to 1 , without cost. The other half are shoppers, without such a production capacity. All members in a household share consumption equally.

In every period $t$, a fraction $n_{t}^{j}$ of household-j's members, producers and shoppers, are linked to the credit system, while the remaining fraction $1-n_{t}^{j}$ are not. Each linked shopper has an established bilateral relationship with a producer to buy his consumption good through a credit-link, $c_{t}^{c, j}$, subject to the capacity constraint $c_{t}^{c, j} \leq 1$. Symmetrically, each linked producer has a bilateral relationship with a shopper to sell her product on credit, $C_{t}^{c, j}$, subject to the constraint $C_{t}^{c, j} \leq 1$. All non-linked shoppers (producers) go to a centralized market to buy (sell) goods with (in exchange for) cash as anonymous members. Money received by non-linked producers can not be passed to shoppers within the same household until the beginning of the following period.

The timing of events is as follows. At the beginning of every period $t \geq 1$, households convene in the centralized financial market to settle outstanding debts and to accumulate government-issued money and bonds. Both government and private debts mature one period after issued and pay the same nominal risk-free rate. Household- $j$ enters this market with the cash obtained from selling a part of the common endowment at $t-1$, denoted by $\widetilde{M}_{t-1}^{j}$, with some maturing government bonds, inclusive of interest, $\left(1+i_{t-1}\right) B_{t-1}^{j}$, some invoices over other households, corresponding to the amount of goods sold on credit during last period, $\left(1+i_{t-1}\right) P_{t-1} C_{t-1}^{c, j}$ and, symmetrically, some debts corresponding to last period's credit-financed purchases, $\left(1+i_{t-1}\right) P_{t-1} c_{t-1}^{c, j}$. The terms $B_{t-1}^{j}, i_{t-1}$ and $P_{t-1}$ are, respectively, bond holdings, the nominal interest rate and the general price level. ${ }^{14}$ The government participates

\footnotetext{
${ }^{13}$ Previous formal applications of models with financial innovation are either restricted to economies with exogenously determined inflation, as in Ireland (1995) and Uribe (1997), or to one-period or steady state analyses, as in Chang (1994) and Sachs (1995), respectively. The approach taken here imposes the necessity of some simplifying assumptions as I am dealing with explosive endogenous inflation paths and sudden changes of regime.

${ }^{14} \mathrm{I}$ am already assuming that all goods are traded at the same relative value. Given the symmetry imposed in endowments and preferences this turns out to be true in the competitive equilibria analyzed later.
} 
in this market redeeming maturing bonds, collecting seigniorage (i.e. money injections by the central bank) and taxes (assumed to be paid in cash), and issuing new bonds. The household's constraint in this market is

$$
M_{t}^{j}+B_{t}^{j}+P_{t} \tau_{t} \leq \widetilde{M}_{t-1}^{j}+\left(1+i_{t-1}\right)\left(B_{t-1}^{j}+C_{t-1}^{c, j}-c_{t-1}^{c, j}\right) \equiv W_{t}^{j}
$$

where $\tau_{t}$ is the lump-sum tax and $\widetilde{M}_{t-1}^{j}$ is the household's stock of monetary balances at the end of the previous period and, hence, it satisfies $\widetilde{M}_{t}^{j} \geq\left(1-n_{t}^{j}\right) P_{t}$. Households are precluded from issuing money, i.e.

$$
M_{t}^{j} \geq 0
$$

Once households rearrange their financial portfolios, non-linked producers engage in a process of finding shoppers for their goods to establish a credit-link. A free producer finds an opportunity to establish a credit link with a shopper with a probability $\gamma<1$. In such an event the producer may chose to invest in the link by paying a utility cost of $\theta .{ }^{15}$ In that case, the shopper commits to redeem the resulting debt plus the interest rate in exchange for money in the financial market during the following period. ${ }^{16}$

Symmetrically, as in Ireland (1995), I assume that the households' credit capacity is subject to a form of depreciation. In particular, links have on average a finite life, as they are subject to a constant probability of termination at the beginning of each period equal to $1-\delta .{ }^{17}$ This assumption is critical for the arguments developed later. In practical terms, it implies that current individual decisions on the mix of money and credit may have effects beyond the current date and, hence, it works as a simple device aimed at capturing the presence of hysteresis in the demand for real balances.

While there is uncertainty at the individual agent level (shopper and producer), the assumption of a continuum of agents within each household implies that at the household level there is no uncertainty on the total measure of the flows of new and existing links. Thus, the law of motion governing the measure of credit-linked producers within household- $j$ can be expressed as:

$$
n_{t}^{j}=\gamma\left[1-\delta n_{t-1}^{j}\right] \lambda_{t}^{j}+\delta n_{t-1}^{j}
$$

where $\lambda_{t}^{j} \in[0,1]$ captures the proportion of producers that take advantage of an opportunity to create a credit-link. Notice that in writing (3), it is assumed that the set of non-linked producers who are eligible to meet a free shopper includes those whose link has just vanished at the beginning of this period.

Then, the centralized market opens. In this market producers who do not deliver their stock of goods on credit sell their production in exchange for money. Here, the following standard cash-in-advance

\footnotetext{
${ }^{15} \mathrm{~A}$ credit-link will generally create some monopolistic rents for the counterparts. As the interest here is in the evolution of the aggregate stock of real balances and, in turn, inflation, I consider a very simple (and extreme) rule governing the sharing of the benefits arising from a match: I assume that the producer pays the fixed utility-cost and leaves the shopper with an infinitesimal share of the monopolistic pecuniary rents of the match. As participating in a this sort of credit contract is costless for the shopper, he is happy to accept any strictly positive payment. For notational simplification, I omit that negligible transfer in the forthcoming expressions.

${ }^{16}$ The assumptions of a constant probability of arrival of a credit-link opportunity and the symmetric proportion of linked producers and shoppers are compatible with a random matching framework in which each individual, shopper or producer, can only commit to maintain a single credit-link and the matching function exhibits constant returns to scale in the number of non-linked agents on both sides of the market and a linear time-invariant total-efficiency parameter $\gamma$.

${ }^{17}$ Similarly, Uribe (1997) assumes that the stock of "social experience" in transacting with dollars, rather than with the local currency, depreciates at an exogenous constant rate.
} 
constraint applies,

$$
c_{t}^{m, j} \leq \frac{M_{t}^{j}}{P_{t}}
$$

where $c_{t}^{m, j}$ refers to the total measure of goods consumed by household- $j$ that are purchased with cash. Finally, the members of the household join to consume the shoppers' purchases. In making its choices at $t$, the household must respect the following flow of funds constraint

$$
\frac{W_{t+1}^{j}+i_{t} \widetilde{M}_{t}^{j}}{1+i_{t}}+P_{t}\left(c_{t}^{m, j}+c_{t}^{c, j}\right) \leq P_{t}\left(1-\tau_{t}\right)+W_{t}^{j}
$$

and a borrowing constraint that rules out games à la Ponzi

$$
\lim _{T \rightarrow \infty} W_{T}^{j} / \prod_{t=1}^{T-1}\left(1+i_{t}\right) \geq 0
$$

All households enter period 1 with the same financial wealth, in an amount exogenously given: $W_{1}^{j}=W_{1}$. Also, the measure of credit-linked producers at the beginning of period 1 (just before the destruction of some of these links) is given by history and identical across households: $n_{0}^{j}=n_{0}$.

Subject to the set of constraints in (1), (2), (3), (4), (5), and (6), household- $j$ chooses a path for $\left\{c_{s}^{m, j}, c_{s}^{c, j}, M_{s}^{j}, \widetilde{M}_{s}^{j}, B_{s}^{j}, n_{s}^{j}, \lambda_{s}^{j}\right\}_{s=t}^{\infty}$ in order to maximize

$$
U_{t}=\sum_{s=t}^{\infty} \beta^{s-t}\left\{\ln c_{s}^{j}-\theta \gamma\left[1-\delta n_{s-1}^{j}\right] \lambda_{s}^{j}\right\}
$$

where $c_{s}^{j}=c_{s}^{m, j}+c_{s}^{c, j}$.

The necessary and sufficient conditions associated with the household's optimization problem are (1), (5), and (6) holding with equality and,

1. The intertemporal allocation of consumption satisfies the Euler equation

$$
\frac{c_{t+1}^{j}}{c_{t}^{j}}=\beta\left(1+i_{t}\right) \frac{P_{t}}{P_{t+1}}
$$

2. When facing an opportunity, a producer decides to establish a credit-link and pay the fixed utilitycost if $\Psi_{t}>\theta$, she is indifferent if $\Psi_{t}=\theta$ and forgoes the opportunity otherwise. The value function $\Psi_{t}$ captures the discounted sum of the expected savings, in terms of the inflationary tax, delivered by a credit-link and is given by

$$
\Psi_{t}=\frac{\sum_{s=1}^{\infty} \delta^{s-1} \phi_{t} x_{t+s}}{\prod_{l=0}^{s-1}\left(1+i_{t+l}\right) \frac{P_{t+l}}{P_{t+l+1}}}
$$

where $x_{t+1}$ is the inflation rate between $t$ and $t+1$, i.e. $\frac{P_{t+1}}{P_{t}}-1$, and $\phi_{t}$ is an indicator function capturing whether the producer is using that credit-link. It may take two values: 1 if the producers use the links and 0 otherwise. Clearly, the producer sets $\phi_{t}=1$ if $x_{t+1}>0$, is indifferent between transacting using the credit facility or attending the decentralized market if $x_{t+1}=0$ and decides to trade his endowments in exchange for cash if $x_{t+1}<0\left(\phi_{t}=0\right)$.

3. Since the nominal interest rate is positive in all the scenarios that I consider later, the household optimally minimizes its end-of-period money holdings, i.e. $\frac{M_{t}^{j}}{P_{t}}=c_{t}^{m, j}$ and $\frac{\widetilde{M}_{t}^{j}}{P_{t}}=\left(1-n_{t-1}\right)$. 
The government. The government in this economy collects taxes, issues and redeems bonds and provides the entire stock of money. There is no government consumption. When choosing a combination of policy-instruments, it is restricted by the two following constraints. First, a period-by-period flow of funds constraint,

$$
B_{t}+M_{t}+P_{t} \tau_{t}=\left(1+i_{t-1}\right) B_{t-1}+M_{t-1}
$$

where $M_{t}$ and $B_{t}$ represent the government supply of money and bonds at time $t$, respectively. Second, an intertemporal constraint given by

$$
\left(1+i_{t-1}\right) B_{t-1}=\sum_{s=0}^{\infty} \frac{P_{t+s} \tau_{t+s}+M_{t+s}-M_{t+s-1}}{\prod_{l=1}^{s}\left(1+i_{t+l}\right)}
$$

where the initial stock of nominal government-issued assets, $B_{0}$ and $M_{0}$, is taken as given.

Regarding monetary policy, I consider two alternative policy regimes:

Fiscal-dominance regime. During this first regime, operating from period 1 to $T>2$ (including both), the government sets an exogenous target for seigniorage. Money supply is then adjusted to satisfy a seigniorage requirement, denoted by $\alpha$, according to the following rule

$$
M_{t}=P_{t} \alpha+M_{t-1} \quad(1 \leq t \leq T)
$$

Monetary-dominance regime. This regime is implemented at $T+1$. From that period on, the government targets a unique sequence of inflation rates by adjusting money supply accordingly. For notational simplicity and without loss of generality, I assume that the targeted level of inflation under this regime is constant and denote it by $x^{L}$.

As the model admits multiplicity of equilibria when the government operates by choosing the amount of money supplied in the financial market in the latter regime, some of them hyperinflationary, it is also assumed that the government is credibly committed to respond to upwards deviations from the inflation target by backing the stock of money according to the following strategy. Taking $P_{T}$ and the aggregate equilibrium stock of money at that date, $M_{T}$, as given, the government announces a sequence of money supplies $\left\{M_{t}\right\}_{t=T+1}^{\infty}$. Such a sequence of money supplies will map into a unique sequence of equilibrium inflation rates if and only if the demand for real balances and, hence, the price level follow a unique path from $T+1$ on. Let us denote this sequence of prices as $\left\{P_{t}^{G}\right\}_{t=T+1}^{\infty}$, whose exact elements are understood to depend on $\left\{M_{t}\right\}_{t=T+1}^{\infty}, M_{T}$ and $P_{T}$, and satisfy $\frac{P_{T+1}^{G}}{P_{T}}=\frac{P_{T+s+1}^{G}}{P_{T}^{G}+s}=1+x^{L}$, for $s=1, \ldots, \infty$. Then, in view of an arbitrary price $P_{t}>P_{t}^{G}$ at any $t \geq T+1$, the government reacts by offering the households the possibility of redeeming each monetary unit in exchange for $\frac{1}{\widetilde{P}_{t}}$ bonds, where $P_{t}^{G} \leq \widetilde{P}_{t}<P_{t}$. Obviously, such a deal creates an arbitrage opportunity which is not compatible with individual optimization and, hence, any $P_{t}$ above the one consistent with the government's inflation target will not be part of an equilibrium, as formally defined below. ${ }^{18}$

\footnotetext{
${ }^{18}$ This backing scheme resembles the one considered by Obstfeld and Rogoff (1983) and Nicolini (1996). Notice that the credibility of this backing-scheme hinges on the households' expectation about a current and/or future fiscal adjustment consistent with the endogenous higher supply of government bonds. Specifically, credibility of this government's contingent strategy requires the commitment to increase the discounted stream of taxes by an amount equal to $\frac{M_{t}}{\widetilde{P}_{t}}$.
} 
As shown later, in most cases after the reform there will be a upward adjustment in the demand for real balances. Thus, a constant targeted $x^{L}$ over this regime will require money injections, i.e. $M_{t}>M_{t-1}$ for $t \geq T+1$, which in turn implies that the government will earn some seigniorage whose amount is (endogenously) driven by the path followed by the stock of real balances. Therefore, in this regime the supply of bonds and the sequence of taxes must be adjusted to satisfy (10) and (11).

Equilibrium. In the remaining of the paper, I restrict attention to symmetric competitive equilibria defined as

Definition 1 A perfect-foresight symmetric competitive equilibrium in this economy is a collection of sequences $\left\{c_{s}^{m}, c_{s}^{c}, M_{s}, \widetilde{M}_{s}, B_{s}, n_{s}, \lambda_{s}, \phi_{s}, P_{s}, i_{s}\right\}_{s=t}^{\infty}$ and a government policy such that the following conditions are satisfied: 1) Households maximize their utility subject to the initial conditions, $W_{1}$ and $n_{0}$, and the constraints (1)-(6), taking as given the price and interest rate sequences and the government policy. 2) The government satisfies its budget constraints (10) and (11). 3) All markets clear at each date.

(where I have dropped for simplicity the household's superscript $j$ ). Note that this definition is sufficiently broad so as to apply to the two fiscal-monetary regimes described before.

\section{Speculative hyperinflations}

In this section I check the ability of the model developed before to (qualitatively) account for the empirical facts listed earlier and to provide an answer to the following question: when is an orthodox fiscal-monetary reform effective to prevent a extreme speculative hyperinflation? To this aim I first characterize two extreme paths of the stock of real balances that will be extensively used in the arguments developed later and, based on the stylized facts presented before, I introduce several general conditions on some parameters of the model. Then, I examine the conditions under which an extreme speculative hyperinflation, whose exact definition is given later, is possible. Throughout this section I assume that the government credibly commits to reform its fiscal-monetary plan at some future date $T+1$, regardless of the state of the economy at that moment. ${ }^{19}$ In section 5 I consider an alternative (state-contingent) rule for abandoning the fiscal-dominance regime showing that the key properties of the analysis conducted under the benchmark case of a fixed-date reform continue to hold under this alternative specification of government policy.

Let us consider the two extreme cases in which all households either exploit the possibility to establish a credit-link whenever possible (thus setting $\lambda_{t}=1$ ) or refuse to invest in the credit technology at all $\left(\lambda_{t}=0\right)$ over the fiscal-dominance regime. Assuming the former case, the economy-wide measure of

\footnotetext{
${ }^{19}$ The assumption that the public knows with certainty the date of the reform is followed by Bental and Eckstein (1990) and Paal (2000).
} 
producers with a credit-link at $t$, according to (3), is given by

$$
n_{t}=\gamma+\delta(1-\gamma) n_{t-1}
$$

Thus, denoting by $m_{t}$ the proportion of producers that sell their goods in exchange for money, i.e. $m_{t}=1-n_{t}$, we can write

$$
m_{t}=(1-\gamma)\left[1-\delta\left(1-m_{t-1}\right)\right]
$$

From the equilibrium condition $M_{t}=\widetilde{M}_{t}$, it follows that $m_{t}$ above represents the end-of-period stock of real balances in the economy, which may take values in the unit interval as long as $i_{t}>0$.

Equation (14) captures the law of motion of $m$ conditional on every producer investing in the credit technology at the highest pace. Conversely, when no new credit-links are made, it can be readily verified that the degree of monetization evolves according to

$$
m_{t}=1-\delta\left(1-m_{t-1}\right)
$$

Henceforth, for notational simplicity I will refer to the sequence $\left\{m_{t}\right\}_{t=1}^{T-1}$ in which each element satisfies the law of motion (14) [(15)] as $\widetilde{m}^{I}\left[\widetilde{m}^{N}\right]$ and denote each of its elements as $m_{t}^{I}\left[m_{t}^{N}\right]$, where the superscripts $I$ and $N$ stand for invest and no invest, respectively.

Next, I introduce the following general assumptions which will be maintained throughout unless otherwise noted.

Assumption 1 (Ex post effective reform). The inflation rate targeted in the post-reform monetary-dominance regime, $x^{L}$, is bounded above by

$$
x^{L} \equiv x_{T+s}<\min \left\{x_{T}, \frac{\theta}{\sum_{s=1}^{\infty} \beta^{s} \delta^{s-1}}\right\}, \quad s \geq 1
$$

The bounds above imply, first, that the change of regime always leads to a fall in inflation at the time of the reform, regardless of the history up to that date (i.e. $x^{L}<x_{T}$ ) and, second, that the reform is always successful in stopping an eventual "flight from money" from the time of its implementation on (i.e. $\Psi_{T}<\theta$, which is equivalent to $x^{L}<\theta\left\{\sum_{s=1}^{\infty} \beta^{s} \delta^{s-1}\right\}^{-1}$ ). ${ }^{20}$ Thus, in equilibrium $\lambda_{s}=0, s \geq T$. Both features are clearly consistent with the evidence described before.

Assumption 2 (Feasibility of the seigniorage target). The level of seigniorage collected over the fiscal-dominance regime, $\alpha$, is bounded above by

$$
\alpha<\alpha^{\max }=m_{T-1}^{I}
$$

When this inequality holds, the amount of seigniorage targeted by the government before the implementation of the reform is feasible even when every household invests in the credit technology in every period $t=1, \ldots, T-1$, so that $m_{T-1}$ takes its minimum possible value. Implicit in this argument is the fact

\footnotetext{
${ }^{20}$ In writing the term in the right side of this inquality, we note that the real return on debts, $r$, is constant over time, $1+r \equiv\left(1+i_{t}\right) \frac{P_{t}}{P_{t+1}}=\beta^{-1}$, a result that follows from the goods-market clearing condition and the Euler equation (8).
} 
that households do not invest in the credit technology at $T$. This is consistent with the class of reforms considered in assumption 1.

Assumption 3 (Positive history-dependence). The targeted level of seigniorage satisfies

$$
\alpha>1-\delta
$$

This condition implies that, regardless of the evolution of the degree of monetization over the fiscaldominance regime, i.e. both if $m_{t}$ follows (14) or (15), the resulting equilibrium inflation rate, $x_{t}$, can be expressed as decreasing function of the last-period degree of monetization, $m_{t-1}$. To see this, let us write (12) as

$$
x_{t}=\frac{m_{t-1}}{m_{t}-\alpha}-1, \quad 2 \leq t \leq T
$$

Then, using (14) and (15) to express $m_{t}$ as a function of $m_{t-1}$, and focusing on its two extreme values, $m_{t}^{I}$ and $m_{t}^{N}$, we can write

$$
\begin{aligned}
& \left.\frac{\partial x_{t}}{\partial m_{t-1}}\right|_{m_{t-1}=m_{t-1}^{I}}<0 \Leftrightarrow \alpha>(1-\delta)(1-\gamma) \\
& \left.\frac{\partial x_{t}}{\partial m_{t-1}}\right|_{m_{t-1}=m_{t-1}^{N}}<0 \Leftrightarrow \alpha>1-\delta
\end{aligned}
$$

Thus, as $\gamma<1$, the inequality in (18) is a sufficient condition for the inflation rate to be negatively related to $m_{t-1}$, regardless of the law of motion of $m$. The following result is a direct consequence of the monetary supply rule (19) and the laws of motions (14) and (15). Given $\delta>0$, if assumption 3 holds then the following inequalities are satisfied

$$
\begin{aligned}
& x_{t}^{I}>x_{t}^{N} \\
& x_{t}^{I} \geq x_{t-1}^{I} \text { and } x_{t+1}^{N} \leq x_{t}^{N}
\end{aligned}
$$

where $x_{t}^{I}\left[x_{t}^{N}\right]$ is the inflation rate satisfying (19), conditional on $m$ following the law of motion (14) [(15)]. Thus, it follows that, for a sufficiently high level of seigniorage, the inflation rate associated with the sequence $\widetilde{m}^{I}$ is always higher than the corresponding to $\widetilde{m}^{N}$. Also from the above inequalities, we learn that for a sufficiently high level of seigniorage a decreasing $m$-sequence is associated with an increasing sequence of inflation rates and vice versa.

The rationale behind assumption 3 is a simple one: by restricting the volume of seigniorage to satisfy (18), we focus on fiscal-dominance regimes along which a higher degree of monetization is associated with a lower inflation rate. This idea resembles the one underlying the analyses based on the interpretation of seigniorage as a tax paid by money holders, along the increasing arm of an inflation-tax Laffer curve, in the sense that a higher tax base (real balances or degree of monetization) needs a lower tax rate (inflation) to yield the same total revenue (seigniorage). As (18) imposes a lower bound on seigniorage or, alternatively, a lower bound on the degree of persistence of the credit technology $(\delta)$, it is not at odds with the common view of high levels of seigniorage being, at least in part, responsible for hyperinflationary processes and with the empirical evidence presented in section 2 regarding the slow recovery of the degree of monetization observed after a hyperinflation. 
Based on the two extreme monotonic $m$-paths just described, I define an extreme speculative hyperinflation as follows.

Definition 2 An extreme speculative hyperinflation is an equilibrium path along which real balances follow the sequence $\widetilde{m}^{I}$ when an equilibrium containing $\widetilde{m}^{N}$ is also possible.

By associating a hyperinflationary path with $\widetilde{m}^{I}$, I focus on an equilibrium in which the prospect of a reform is irrelevant for the actions of the households at any date before the implementation of the reform (i.e. up to $T-1$, inclusive), that is, the expectation of the reform along such a path, according to its definition, is not effective to avoid a gradual process of demonetization. Moreover, the existence of an equilibrium containing this particular sequence is a necessary and sufficient condition for the existence of any other equilibrium path along which the expectation of a reform does not exert any preventive role. This feature of the sequence $\widetilde{m}^{I}$ will be critical in when analyzing the joint occurrence of hyperinflationary equilibria and (endogenous) reforms. The notion of speculative equilibrium employed in this paper refers to a situation in which more than one equilibrium is a priori possible, thus allowing expectations to play a role in selecting a particular outcome. Allowing for the possibility of an equilibrium containing the sequence $\widetilde{m}^{N}$ fulfills this requirement. Yet it must be acknowledged that feasibility of this particular path is not a necessary condition for the existence of a path along which the reform has effects before its implementation, as discussed later. Overall, definition 1 does not directly account for the possible (co)existence of some non-monotonic $m$-paths, but focusing on just two paths will prove helpful to compare the results of this paper with those analyses of expectations-driven hyperinflations based on the existence of hump-shaped Laffer curve, as those in Sargent and Wallace (1987), and Bruno and Fischer (1990).

Before stating formally the necessary conditions for an extreme speculative hyperinflation, I introduce some notation. I use the superscript $\kappa=I, N$ in the value function $\Psi_{t}^{\kappa}$ to denote the corresponding function associated with each extreme $m$-sequence, i.e.

$$
\Psi_{t}^{\kappa}=\sum_{s=1}^{T-t} \beta^{s} \delta^{s-1} x_{t+s}^{\kappa}+\frac{\beta^{T-t+1} \delta^{T-t}}{1-\beta \delta} \phi_{t} x^{L}
$$

Thus, $\Psi_{t}^{I}$ captures the (gross) profit given by a credit link when all households exploit every opportunity for investment in the credit technology in each period within the pre-reform period. Denoting by $\underline{\Psi}^{I}$ the lowest element in the sequence $\left\{\Psi_{t}^{I}\right\}_{t=1}^{T-1}$, it follows from (9) that the necessary and sufficient condition for the existence of an equilibrium consistent with $\widetilde{m}^{I}$ is

$$
\underline{\Psi}^{I} \geq \theta
$$

Combining (14), (19) and (22) we learn about the effects of the parameters and policy variables on condition (23). Higher values of $\beta$ increase the total return of the investment in a credit-link, thus raising $\Psi_{t}^{I}$, and, hence, $\underline{\Psi}^{I}$. A similar effect comes from $\delta$, as higher $\delta$ means a longer average life for a link. Also, from (14), higher $\gamma$ contributes to a more rapid demonetization and, thus, to a higher sequence 
of future inflation rates and a higher value for the credit-technology at any $t$. This latter effect is also caused by a lower initial condition, $m_{0}$. It follows trivially that low values for the cost of establishing a credit link, $\theta$, widen the set of conditions under which (23) holds. The effect of the policy instruments, $\alpha, T$ and $x^{L}$, on condition (23) is also very intuitive. High seigniorage goes in hand with high inflation rates, given a path for $m$, thus pushing $\underline{\Psi}^{I}$ up. A restrictive monetary supply over the post-reform period contributes, given every thing else, to keep inflation low also in the pre-reform period, since low values for $x^{L}$ reduce the expected return of a credit-link. Also, an early reform (low $T$ ) reduces the incentives to invest in the credit technology, since it shortens the period over which that investment yields high inflation-savings (the pre-reform period). Finally, the effect of time on $\Psi_{t}^{I}$ is likely to be non-monotonic due to a discount-effect. Indeed, all the numerical simulations discussed later yield a hump-shaped $\Psi_{t}^{I}$ function, i.e. the lowest values are located at the beginning and at the end of the pre-reform period.

Likewise, the function $\Psi_{t}^{N}$ captures the benefits for a single household from investing in a credit-link conditional on that link being the only one made from that period on. As assumptions 1 and 3 hold, by combining (15), (19) and (22) we learn that $\Psi_{t}^{N}$ falls as time passes. Hence, the following sign condition is necessary and sufficient for the existence of an equilibrium containing $\widetilde{m}^{N}$

$$
\Psi_{1}^{N} \leq \theta
$$

Clearly, the influence of the parameters and policy variables on condition (24) is the opposite one with respect to (23), that is, low values of $\beta, \alpha, \delta, x^{L}$ and $T$, and high values of $m_{0}$ and $\theta$ run in favor of the feasibility of an equilibrium with the sequence $\widetilde{m}^{N}$.

Combining (23) and (24), we learn that an extreme speculative hyperinflation is possible in this environment if the following condition holds

$$
\Psi_{1}^{N} \leq \theta \leq \underline{\Psi}^{I}
$$

In order to investigate how the degree of fiscal pressure in the pre-reform period relates to the possibility of multiple equilibria, in the following proposition I characterize the threshold conditions (23) and (24) as functions of $\alpha$, taking everything else as given.

Proposition 1 Let us define the following two limit values for $\theta$,

$$
\begin{aligned}
\bar{\theta} & \equiv \lim _{\alpha \chi^{\max }} \Psi_{T-1}^{I} \\
\underline{\theta} & \equiv \lim _{\alpha \searrow 1-\delta} \Psi_{1}^{N}
\end{aligned}
$$

If $\underline{\theta} \leq \theta \leq \bar{\theta}$, then there exist a unique $\alpha^{I}$ such that $\underline{\Psi}_{t}^{I}\left(\alpha^{I}\right)=\theta$ and a unique $\alpha^{N}$ such that $\Psi_{1}^{N}\left(\alpha^{N}\right)=\theta$, and both extreme equilibria are possible if $\alpha^{I}<\alpha^{N}$ and $\alpha \in\left[\alpha^{I}, \alpha^{N}\right]$.

Proof. The necessity of a bounded $\theta$ is simple. The upper bound $\bar{\theta}$ is defined as the cost of a credit link such that $\widetilde{m}^{I}$ may be part of an equilibrium when $\alpha$ is set arbitrarily close to its maximum 


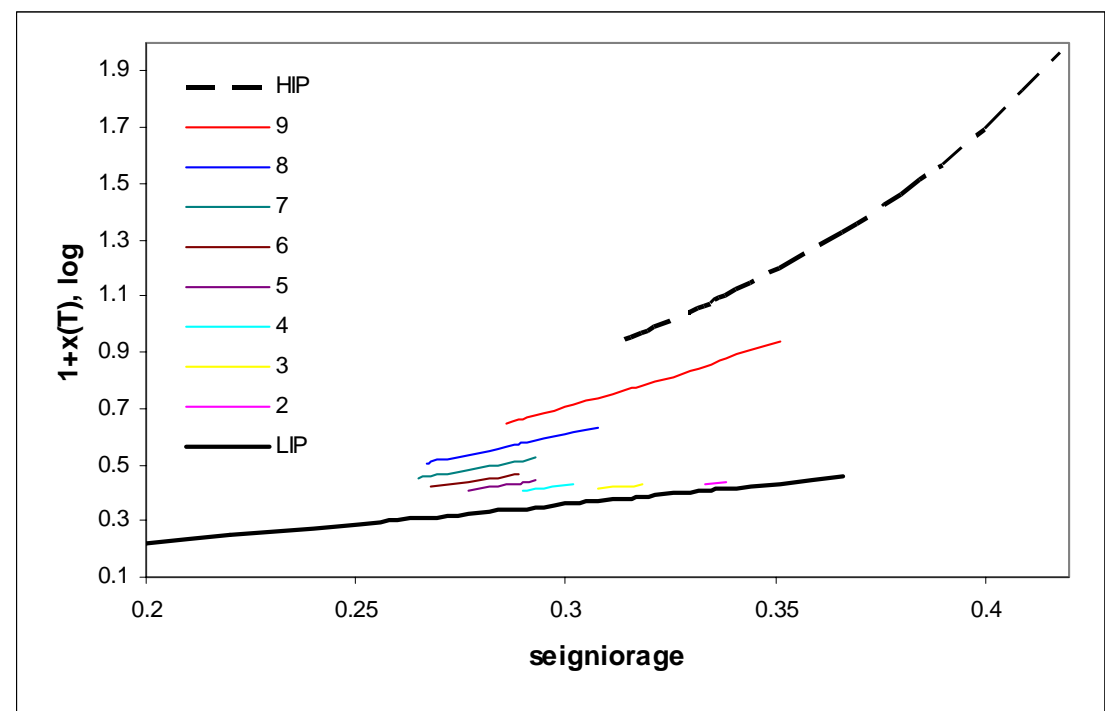

Parameter values: $m_{0}=1, \theta=1.35, \beta=0.8, x^{L}=0.1, \delta=0.9, \gamma=0.15, T=10$. Computed (extreme) threshold seigniorage-values: $\alpha^{N}=0.366$ and $\alpha^{I}=0.314$.

LIP $($ lowest inflationary path $)=\log \left(1+x^{\mathrm{N}}{ }_{\mathrm{T}}\right), H I P($ highest inflationary path $)=\log \left(1+x_{\mathrm{T}}^{\mathrm{I}}\right)$, lines labeled $i=2$ to 9 represent $\log \left(1+x_{\mathrm{T}}\right)$ conditional on $\lambda_{\mathrm{t}}=1$ for $t=1, \ldots, i-1$ and $\lambda_{\mathrm{t}}=0$ for $t>i-1$.

Figure 2: Dynamic Laffer-curve with coexisting extreme paths

sustainable level, $\alpha^{\max }$, as given in (17). In computing $\bar{\theta}$, notice that $\lim _{\alpha{ }^{\max }} x_{T-1}^{I} \rightarrow \infty$, so for finite $T$ and $\theta, \lim _{\alpha \gamma^{\max }} \Psi_{t}^{I} \rightarrow \infty>\theta$ for $1 \leq t \leq T-2$, and, hence, feasibility of $\widetilde{m}^{I}$ hinges exclusively on the value of $\lim _{\alpha \nearrow^{\max }} \Psi_{T-1}^{I}$. Likewise, the lower bound $\underline{\theta}$ implies that $\theta$ is always sufficiently high so that individuals optimally give up their opportunities to expand their portfolio of credit-links whenever $\alpha$ is set close to its minimum possible value, $1-\delta$, consistently with assumption 3 .

Uniqueness of the threshold values $\alpha^{I}$ and $\alpha^{N}$ and the necessity of an intermediate $\alpha \in\left[\alpha^{I}, \alpha^{N}\right]$, both follow from the fact that $\underline{\Psi}_{t}^{I}$ and $\Psi_{1}^{N}$ are monotonically increasing functions of $\alpha$.

Figure 2 depicts $x_{T}$ (i.e. the last endogenously determined inflation rate) as a function of $\alpha$, for a set of parameters for which $\alpha^{I}<\alpha^{N}$, for the two extreme paths. ${ }^{21}$ This figure shares an important feature with a standard hump-shaped inflation-tax Laffer-curve, namely that some levels of seigniorage can be financed at either a stable and low (or moderate) inflation rate or at an unstable rising one. However, in this economy a speculative hyperinflation will not take place for low values of seigniorage $\left(\alpha<\alpha^{I}\right)$ since the prospect of a future reform renders the investment in the credit technology no profitable enough. Another important feature of this economy is that along a speculative hyperinflationary path inflation is always positively associated with the level of seigniorage, just the opposite result found in the analyses performed by Sargent and Wallace (1987) and Bruno and Fischer (1990), since, in those models, the fact that a speculative hyperinflation is understood as the economy slipping into the decreasing arm of the

\footnotetext{
${ }^{21}$ In addition to these two extreme paths, this figure plots the time $T$ inflation rates arising under non-monotonic paths along which the equilibrium level of monetization, $m$, decreases up to some period $i-1$ and then grows up uniformly from $i$ on.
} 
Laffer-curve implies that one should expect higher rates of inflation when seigniorage is low.

Figure 2 also makes clear that the model is compatible with the main result obtained in the moneymarket partial-adjustment framework employed by Kiguel (1989) and Romer (2001), namely that "too high" seigniorage, i.e. in this model values of $\alpha>\alpha^{N}$, will invariably result in a hyperinflationary path. However, while admitting the potential importance of seigniorage in causing a hyperinflation, this model still allows for equilibrium hyperinflationary paths even when the quantitative measure of fiscal-dominance before the reform is thought to be only "moderate", i.e. values of $\alpha$ falling within the interval $\left[\alpha^{I}, \alpha^{N}\right]$.

I now turn the attention to the analysis of the effects of some parameters of special interest on the amplitude of the interval $\left[\alpha^{I}, \alpha^{N}\right]$, which can be understood as a measure of the scope for a speculative hyperinflation. In particular, in what follows I focus on $\delta, \gamma$ and $x^{L}$. Devoting special attention to $\delta$ and $\gamma$ is obliged here, since these parameters are the critical ingredients that distinguish this economy from one with a standard Cagan-type demand for real balances. The interest on $x^{L}$ follows from the fact that the possibility of hysteresis in the degree of monetization after the reform, which as shown below is a critical necessary condition for a speculative hyperinflation, hinges crucially on the value of $x^{L}$.

Persistency of the credit technology. The possibility of persistent effects of the credit technology beyond the time of the reform is critical for the co-existence of the two extreme equilibria. There are two scenarios in this economy in which the use of credit over the fiscal-dominance-regime is not maintained after the reform: (i) if the government chooses a post-reform inflation target, $x^{L}$, below the cost of using an existing link, i.e. zero; and, (ii) if a credit link is only operative one period, i.e. $\delta=0$. I deal with these two cases in turn.

Proposition 2 If $x^{L}<0$, then an extreme speculative hyperinflation is not possible.

Proof. As $x^{L}<0$, no household would optimally use a credit link after the reform, hence $\phi_{s}=0$ and $m_{s}=1$ for $s \geq T$. Then, exploiting the necessary condition for an extreme speculative hyperinflation (24) and the fact that $\Psi_{t}^{N}$ decreases over time, we can write

$$
\Psi_{T-1}^{N}=\beta \frac{m_{T-1}^{N}}{1-\alpha}<\Psi_{1}^{N} \leq \theta
$$

The other necessary condition (23) requires

$$
\Psi_{T-1}^{I}=\beta \frac{m_{T-1}^{I}}{1-\alpha} \geq \theta
$$

Using $m_{T-1}^{I}<m_{T-1}^{N}$, and combining (26) and (27) we learn that $\Psi_{T-1}^{I}<\Psi_{T-1}^{N} \leq \theta$, which clearly leads to contradiction. Thus $\alpha^{I}>\alpha^{N}$.

This result is intuitive. A commitment to a negative $x^{L}$ implies that if the reform is implemented then $m_{T}$ adjusts instantaneously towards its unique possible equilibrium value: the full monetization 
level, $m_{T}=1$. Critically, the magnitude of the adjustment is history-independent. This implies that just before the reform, at $T-1$, there is a negative relationship between the volume of investment in the credit technology and its return, as illustrated in (27), that renders suboptimal the highest possible level of investment, i.e. that compatible with the equilibrium along which the reform is ex ante ineffective.

The above mechanism lies at the core of the speculative hyperinflationary equilibria rejection mechanism studied by Obstfeld and Rogoff (1983). Moreover, as in the economies studied by those authors there is no source of history-dependence at any date (not just at the time of regime change), the reform will not only rule out the extreme hyperinflation but also it will rule out any equilibrium path except one, thus working as an equilibrium selection device. To illustrate this point, the following proposition describes the equilibrium determination in the limit case in which $\delta=0$.

Proposition 3 If $\delta=0$, then there exists a unique equilibrium.

Proof. As $\delta=0$, in equilibrium it follows that $\phi_{s}=0, m_{s}=1, x_{T}^{I}=\frac{1-\gamma}{1-\alpha}-1$, and $x_{T}^{N}=\frac{1}{1-\alpha}-1$, so $x_{T}^{N}>x_{T}^{I}$. The latter inequality also implies $\Psi_{T-1}^{N}>\Psi_{T-1}^{I}$. Let us consider three alternative cases, depending on the sign of the following differences: $\Psi_{T-1}^{I}-\theta$ and $\Psi_{T-1}^{N}-\theta$.

Case 1. $\Psi_{T-1}^{N} \leq \theta$. As $x_{T}^{I}<x_{T}^{N}$, it follows that $\Psi_{T-1}^{I}<\theta$. Then, the optimal households' decision at $T-1$ is not to invest in the credit technology, i.e. there is no $\lambda_{T-1} \in(0,1]$ such that $\beta\left(\frac{1-\lambda_{T-1} \gamma}{1-\alpha}-1\right)>\theta$. Thus, in equilibrium, $m_{T-1}=m_{T}=1$. The same argument clearly applies to any period $t \in[1, T-1]$, so, from (19), we learn that the equilibrium inflation rate is also uniquely determined (and constant) over the pre-reform regime, i.e.

$$
x_{t}^{(1)}=\frac{1}{1-\alpha}-1 \text { for } 2 \leq t \leq T \text {. }
$$

Case 2. $\Psi_{T-1}^{I} \geq \theta$. In this case $\Psi_{T-1}^{N}>\theta$ must hold and the households optimally decide to exhaust their opportunities to invest in the credit technology at $T-1$, so that $\lambda_{T-1}=1$ and $m_{T-1}=1-\gamma$. Then, the lowest possible inflation at $T-1$ is $\frac{1-\gamma}{1-\gamma-\alpha}-1>x_{T}^{I}>\frac{\theta}{\beta}$. Thus, the households optimally set $\lambda_{T-2}=1$, and, applying this argument backwards, we learn that in equilibrium $\lambda_{t}=1$ and $m_{t}=1-\gamma$ for $t=1, \ldots, T-1$. Then, given a unique equilibrium sequence $\left\{m_{t}\right\}_{t=1}^{T-1}$, it follows that there is also a unique equilibrium sequence of inflation rates satisfying

$$
x_{t}^{(2)}= \begin{cases}\frac{1-\gamma}{1-\gamma-\alpha}-1, & 2 \leq t \leq T-1 \\ \frac{1-\gamma}{1-\alpha}-1 & t=T\end{cases}
$$

Case 3. $\Psi_{T-1}^{N}>\theta$ and $\Psi_{T-1}^{I}<\theta$. This case is clearly incompatible with the limiting values of $\lambda_{T-1}$, 0 and 1 . First, $\lambda_{T-1}=0$ can not be optimal since the inflation rate resulting from the highest level of monetization, $m_{T-1}^{N}=1$, is higher than the unit cost of a credit-link. Symmetrically, $\lambda_{T-1}=1$ can not be optimal either, for the inflation rate consistent with $m_{T-1}^{I}=1-\gamma$ falls below the cost of a link. Thus, in a symmetric equilibrium, the household chooses an intermediate $\lambda_{T-1} \in(0,1)$, i.e. some producers 
within the household invest and some others, while having the opportunity, do not. But this implies that at the margin the household must be indifferent between establishing a link or not. Therefore, the (unique) equilibrium inflation rate at $T$ satisfies $\beta x_{T}=\theta$ and $x_{T} \in\left(x_{T}^{I}, x_{T}^{N}\right)$. Then, we can use (19) to solve for the unique equilibrium $\lambda_{T-1}$, which satisfies

$$
\theta=\beta\left(\frac{1-\lambda_{T-1} \gamma}{1-\alpha}-1\right)
$$

Given a unique $m_{T-1}=1-\lambda_{T-1} \gamma$, we learn that $\frac{1}{1-\lambda_{T-1}-\alpha}-1>x_{T}^{N}>\frac{\theta}{\beta}$, so that the relevant condition governing the households' choice for $\lambda_{T-2}$ is given by the sign of $\beta\left(\frac{1-\gamma}{1-\lambda_{T-1}-\alpha}-1\right)-\theta$. If it is negative, following the same argument as before, the equilibrium inflation rate at $T-1$ is equal to $\frac{\theta}{\beta}$ and (19) can be solved for the unique equilibrium $\lambda_{T-2}$. This iterative process continues up to a period $t^{*}$ at which the following inequality holds,

$$
x_{t^{*}+1}^{I} \equiv \frac{1-\gamma}{1-\lambda_{t^{*}+1} \gamma-\alpha}-1 \geq \frac{\theta}{\beta}
$$

with $\lambda_{t^{*}+1}<1$, in which case, we learn that individual optimality calls for $\lambda_{t^{*}}=\lambda_{t^{*}-1}=\ldots=\lambda_{1}=1$. Thus, the degree of monetization for $t=1, . ., t^{*}$ is $\frac{1-\gamma}{1-\gamma-\alpha}$. Then, given a unique equilibrium sequence $\left\{m_{t}\right\}_{t=1}^{T}$, we can solve for the unique sequence $\left\{x_{t}\right\}_{t=2}^{T}$,

$$
x_{t}^{(3)}= \begin{cases}\frac{1-\gamma}{1-\gamma-\alpha}-1, & 2 \leq t \leq t^{*} \\ \frac{1-\gamma}{1-\lambda_{t^{*}+1} \gamma-\alpha}-1 & t=t^{*}+1 \\ \frac{\theta}{\beta} & t=t^{*}+2, \ldots, T\end{cases}
$$

Using the terminology introduced above, Case 1 corresponds to the an equilibrium containing the $\widetilde{m}^{N}$ and Case 2 to the other extreme case $\left(\widetilde{m}^{I}\right)$. We can then solve for the two critical $\alpha$-thresholds, $\alpha^{N}$ and $\alpha^{I}$, to find the following correspondence relating seigniorage to the equilibrium inflation sequence

$$
\underset{2 \leq t \leq T}{x_{t}}=\left\{\begin{array}{cc}
x_{t}^{(1)} & \text { for } \quad \alpha^{(1)} \leq \alpha^{N} \equiv \frac{\theta}{\beta+\theta} \\
x_{t}^{(2)} & \text { for } \quad \alpha^{(2)} \geq \alpha^{I} \equiv \frac{\beta \gamma+\theta}{\beta+\theta} \\
x_{t}^{(3)} & \text { for } \quad \alpha^{(3)} \in\left(\alpha^{N}, \alpha^{I}\right)
\end{array}\right.
$$

The intuition of this proposition is the following. As $\delta=0$, the reform leads to a unique optimal means-of-transaction portfolio decision over the monetary-dominance regime, which tantamounts to say that the households' optimal actions from $T$ on are completely independent of their actions at any earlier date. In plain words, "the future is independent of past". Then, the ability of the government to implement a monetary rule consistent with an exogenously fixed level of seigniorage implies, in view of (19), that for the unique "possible future" there is a unique "possible past". By imposing $\delta=0$, we get a version of the model that replicates one of the salient features of the Cagan-type demand for real balances function, namely, that the only relevant endogenous variable for the individual's decision of how much money to hold is the next period's expected inflation. Hence, in this critical aspect the 


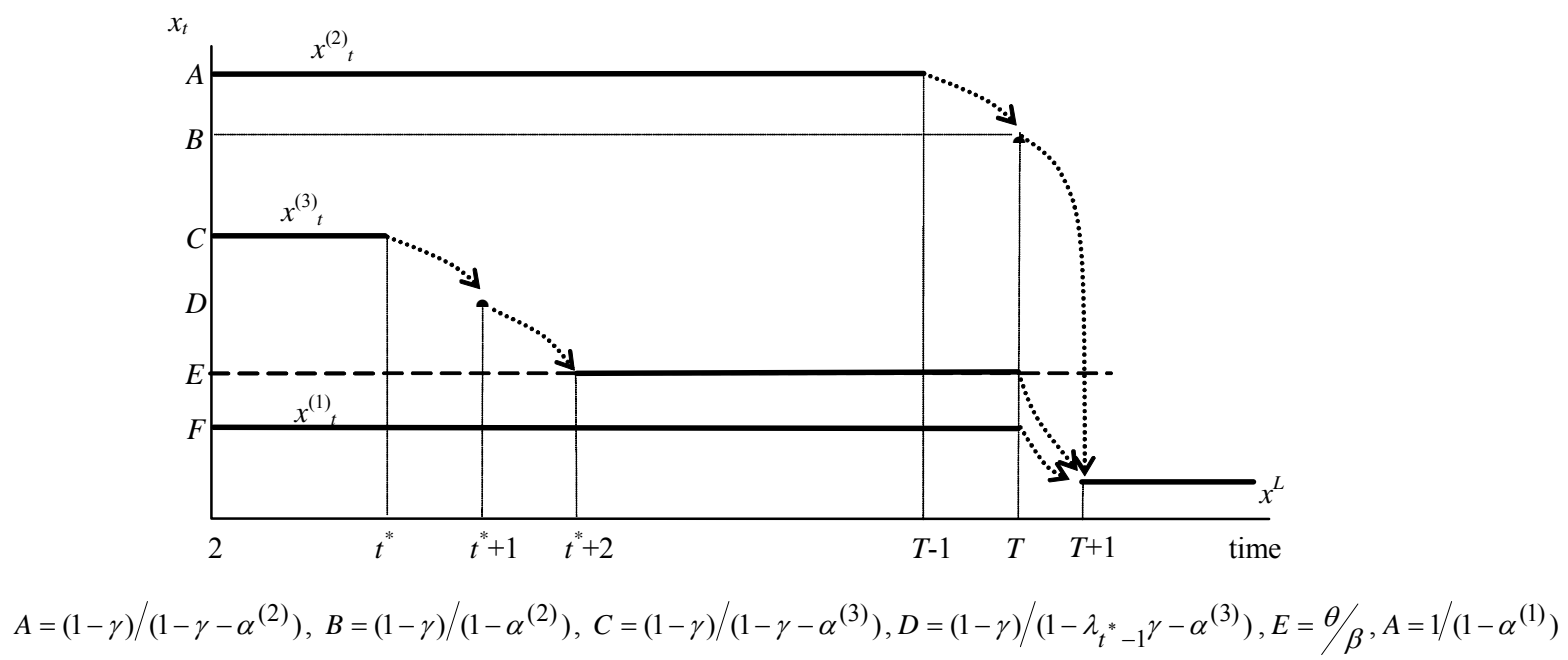

Figure 3: Alternative inflation-paths for $\delta=0$

no-hysteresis version of our economy falls within the general class examined by Obstfeld and Rogoff (1983), and Nicolini (1996), and, not surprisingly, for a given path of government policy choices there is only space for one set of equilibrium beliefs.

The three possible equilibrium inflation sequences in (30) are plotted in figure 3. This figure makes clear one of the "anomalous" features of the Cagan-model in a rational expectations framework, which has been mentioned in the introduction, namely that a higher volume of seigniorage over the pre-reform regime leads to a more pronounced disinflationary path when a reform is expected.

On the contrary, as we allow for possibility of hysteresis in the stock of monetization (i.e. $\delta$ and $x^{L}$ both positive), there is a chance for the coexistence condition (25) to hold. A successful post-reform policy aimed at stabilizing the rate of inflation at a low level induces a unique optimal private behavior from the time of the reform on but it may not be sufficient to induce a unique optimal behavior before its implementation and, hence, private expectations may play a role in selecting a particular equilibrium. Figure 4 contains a numerical example which shows that the difference $\alpha^{N}-\alpha^{I}$ is strictly increasing in $\delta$ for several for several pre-reform time-horizons, such that for a sufficiently high $\delta$, the basic necessary condition for an extreme speculative hyperinflation, $\alpha^{N}-\alpha^{I}>0$, is satisfied.

The speed of demonetization. In some models of hyperinflations the existence of an upper bound in the velocity of demonetization (i.e. the fall in $m$ between two consecutive periods) is a necessary condition to generate a hyperinflationary path when seigniorage is high, such that violations of that threshold lead to a reversal of the dynamics of the model. For example, in the Kiguel-Romer framework with partial adjustment in the money market, a sufficiently high speed of adjustment may invert the sign of the correlation between seigniorage and inflation, yielding disinflationary paths when seigniorage is above the maximum level dictated by the stationary inflation-tax Laffer-curve. A similar effect is also 


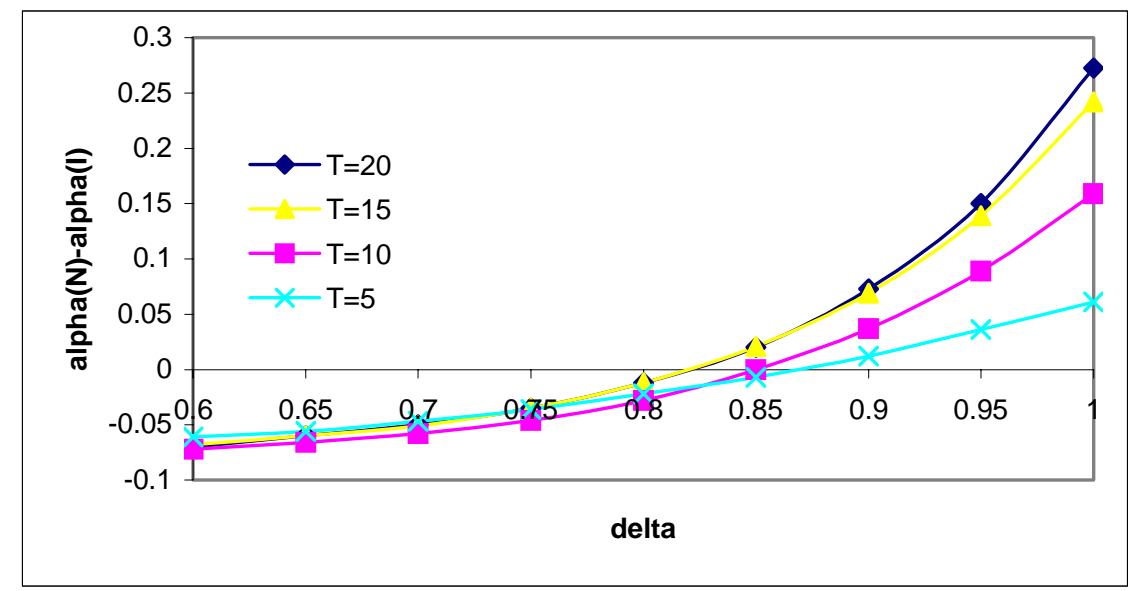

Parameter values: $\mathrm{m}_{0}=1, \theta=1.35, \beta=0.8, x^{L}=0.1, \gamma=0.15$

Figure 4: Effect of $\delta$ on the range of coextistence $\left(\alpha^{N}-\alpha^{I}\right)$

found in some models with backward looking expectations (crude adaptive or quasi-rational expectations as in the modern literature on learning mechanisms). ${ }^{22}$ To put it in simple terms, such a feature implies that should individuals be able to "fly from money" at a sufficiently fast rate, say because there are not important obstacles to access to alternative means of payment (i.e. high $\gamma$ ), we would observe very severe hyperinflations when seigniorage is low and pronounced disinflations with high volumes of seigniorage.

Such a counterintuitive feature is also shared by the version of the model analyzed before when $\delta=0$. The following example illustrates this point. Let us assume an initial situation with a level of seigniorage satisfying $\alpha>\frac{\beta \gamma^{0}+\theta}{\beta+\theta}$. According to (30), individual optimality implies that equilibrium inflation in the pre-reform regime is given by (28), with $\gamma=\gamma^{0}$. Now, let us suppose that $\gamma$ rises up to $\gamma^{\prime}>\gamma^{0}$, such that now $\alpha<\frac{\beta \gamma^{\prime}+\theta}{\beta+\theta}$. This upward adjustment in $\gamma$ moves the economy into the intermediate region in (30), thus lowering the inflation rate at $T$ (since $\frac{1-\gamma^{0}}{1-\alpha}-1>\frac{\theta}{\beta}$ ), and at every date sufficiently close to the reform, at which $\beta x=\theta$ for $\gamma=\gamma^{\prime}$. Further, for sufficiently high $\gamma$ (or low $T$ ) the equilibrium inflation sequence is uniformly lower under $\gamma^{\prime}$ than under $\gamma^{0}$, that is, a more effective mechanism for bringing together unlinked shoppers and producers (i.e. higher $\gamma$ ) results in a lower degree of usage of credit and, thus, at some dates, in lower inflation.

The previous result is reversed as we allow for the possibility of hysteresis after the reform, as formally stated in the following proposition.

Proposition 4 If $\delta>0$ and $x^{L}>0$, then higher $\gamma$ implies (i) a uniformly higher inflation rate along the hyperinflationary equilibrium containing the sequence $\widetilde{m}^{I}$, and (ii) a wider range of coexistence of extreme equilibria, as measured by $\alpha^{N}-\alpha^{I}$.

\footnotetext{
${ }^{22}$ For a discussion of this point in the context of a mechanism of crude adaptive expectations see, e.g. Bruno and Fischer (1990). Lettau and van Zandt (2003) and Adam, Evans and Honkapojha (2005) investigate how the usage of current versus past inflation rates in forming expectations affect the dynamic properties of a standard model of seigniorage under alternative learning rules, showing that under some widely used specifications for the learning rule, the use of updated, rather than lagged, information tends to make an explosive hyperinflation a more unlikely result.
} 


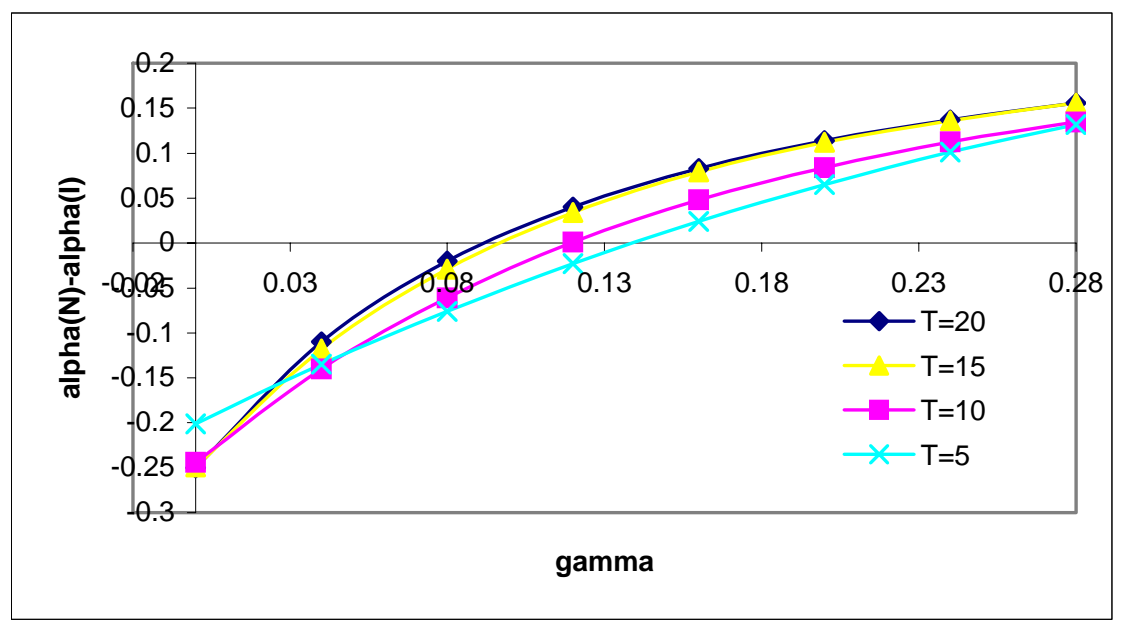

Parameter values: same as in figure 4 with $\delta=0.9$

Figure 5: Effect of $\gamma$ on the range of coextistence $\left(\alpha^{N}-\alpha^{I}\right)$

Proof. (i) Straightforward. Using the definition of $x_{t}^{I}$, we learn that $\frac{d x_{t}^{I}}{d \gamma}>0$.

(ii) By totally differentiating the value function $\Psi_{t}^{I}$ and using the definition of $\alpha^{I}$ in proposition 1 , we obtain that $\frac{d \alpha^{I}}{d \gamma}<0$. Now, using $\Psi_{t}^{N}$, we learn that $\frac{d \alpha^{N}}{d \gamma}=0$. Hence, it trivially follows that $\frac{d\left(\alpha^{N}-\alpha^{I}\right)}{d \gamma}>0$

Thus, when individuals can easily substitute credit for money as an alternative means of carrying out transactions and individuals internalize the persistence of their decisions, a simple and intuitive proposition applies: extreme speculative hyperinflations are more likely outcomes. ${ }^{23}$ Figure 5 contains a numerical example, similar to the one in figure 4 , in which the difference $\alpha^{N}-\alpha^{I}$ is shown to be strictly increasing in $\gamma$.

Some numerical illustrations. Figures $6 \mathrm{~A}$ to $6 \mathrm{~F}$ represent the two extreme shadow-value functions, $\Psi_{t}^{I}$ and $\Psi_{t}^{N}$, together with those associated with $\cup$-shaped $m$-paths, ${ }^{24}$ the time-invariant cost function (left column) and the corresponding sequences of the inflation rate and real balances (right column) for $T=10$. In the three cases, both $\delta$ and $x^{L}$ are strictly positive ( 0.9 and 0.1 , respectively), such that hysteresis in $m$ after the reform is a priori possible and $\alpha^{N}>\alpha^{I}$. The case depicted in the first row (figures $6 \mathrm{~A}$ and $6 \mathrm{~B}$ ) corresponds to a level of seigniorage sufficiently low so that the only feasible equilibrium corresponds to the $\widetilde{m}^{N}$-sequence. Hence, for a given initial condition for $m_{0}$ below $1, m$ grows and $x$ decreases over the pre-reform period. Figures $6 \mathrm{C}$ and $6 \mathrm{D}$ represent a situation with an intermediate level of seigniorage falling within the interval $\left(\alpha^{I}, \alpha^{N}\right)$. Thus, both the $\widetilde{m}^{N}$ - and the $\widetilde{m}^{I}$ -

\footnotetext{
${ }^{23}$ In his classic study on inflationary finance, Nichols (1974) formulates an intuitive principle to avoid hyperinflations, or at least to keep inflation under some control, in face of a given target for seigniorage: restrict the public's access to those assets that may be seen as close substitutes for money. Chang (1994) also points out that policies tending to decrease the usage of foreign currency should reduce inflation. Proposition 4 shows that those reflections are plainly compatible with this model.

${ }^{24}$ The function $\widetilde{\Psi}_{t}$ is also depicted (see the Appendix for its definition) to facilitate the graphic inspection of the fulfillment of the necessary conditions for the occurence of $\cup$-shaped $m$-paths.
} 


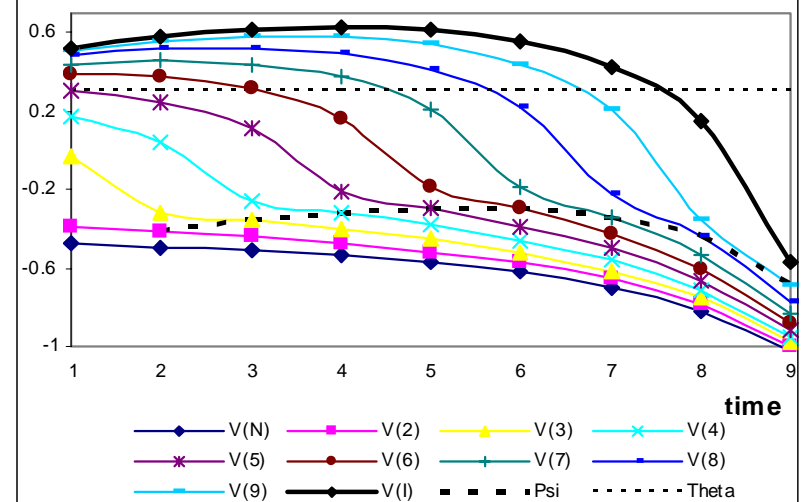

Fig. 6A: Value functions $(\alpha=0.20)$

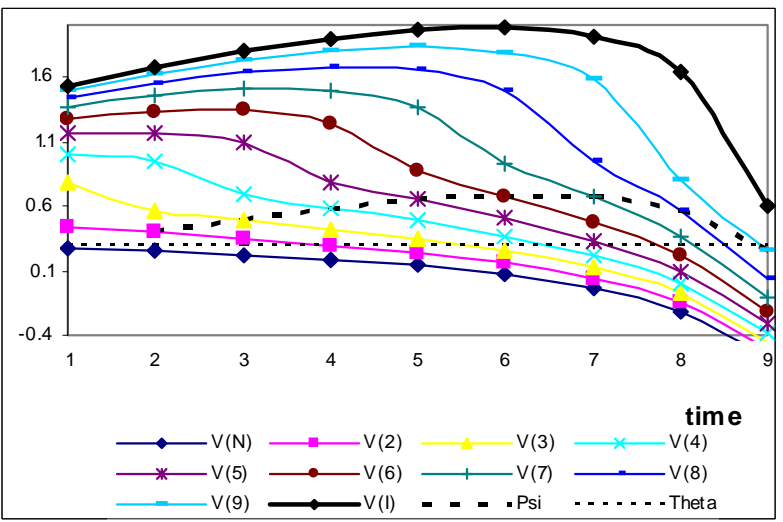

Fig. 6C: Value functions $(\boldsymbol{\alpha}=0.34)$

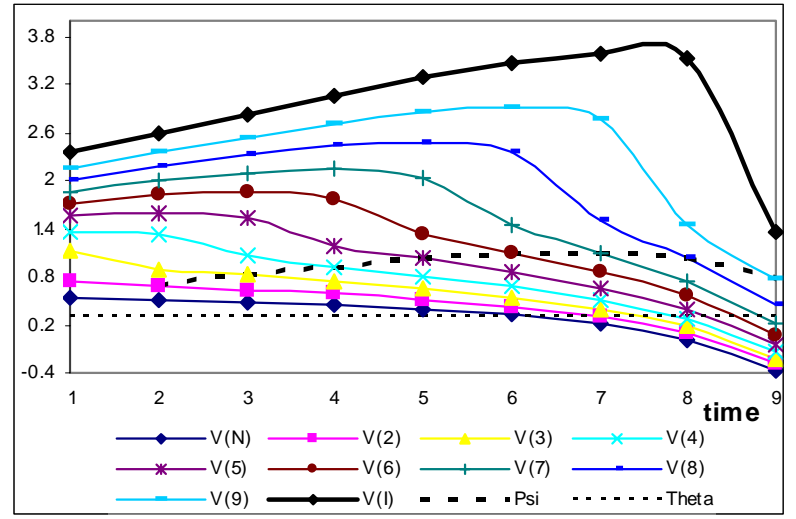

Fig. 6E: Value functions $(\boldsymbol{\alpha}=0.40)$

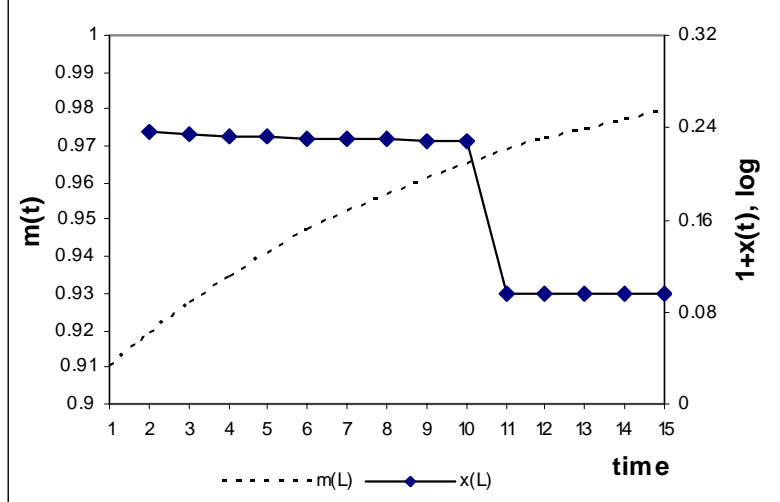

Fig. 6B: Inflation and real balances $(\boldsymbol{\alpha}=0.20)$

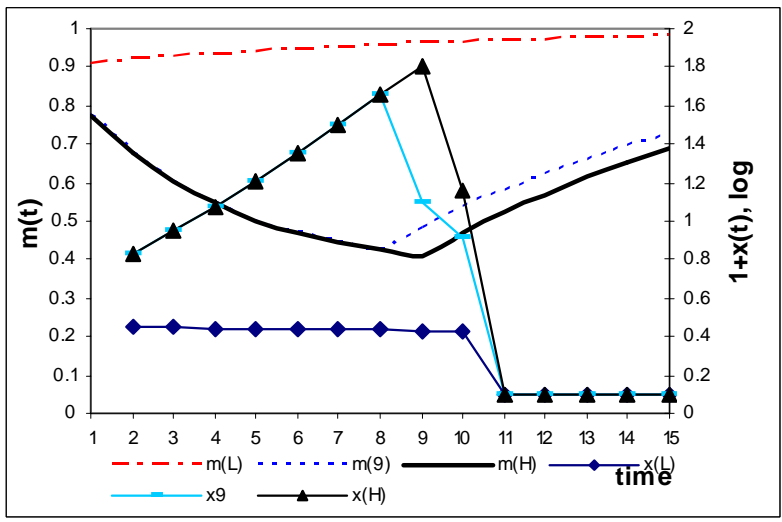

Fig. 6D: Inflation and real balances $(\boldsymbol{\alpha}=0.34)$

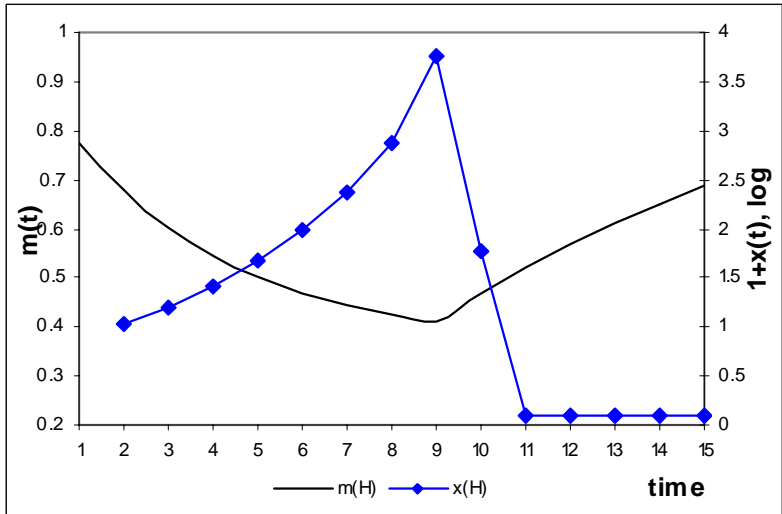

Fig. 6F: Inflation and real balances $(\alpha=0.40)$

Parameter values: $T=10, \mathrm{~m}_{0}=0.9, \theta=1.35, \beta=0.8, x^{L}=0.1, \gamma=0.15, \delta=0.9$. Vertical axis: (natural log of) $\theta$ and $V(\mathrm{i})$ which denotes the value function $\Psi_{\mathrm{t}}$ associated with a $\lambda$-sequence such that $\lambda_{\mathrm{t}}=1$ for $t=1, \ldots, i-1$ and $\lambda_{\mathrm{t}}=$ 0 for $t>i-1 . V(N)$ and $V(I)$ denote, respectively, the extreme value function $\Psi^{N}{ }_{\mathrm{t}}$ and $\Psi_{\mathrm{t}}^{I}$. $P_{S i}$ corresponds to the function $\widetilde{\Psi}_{t}$ defined in the appendix.

Figure 6: Seigniorage and inflation: alternative scenarios 


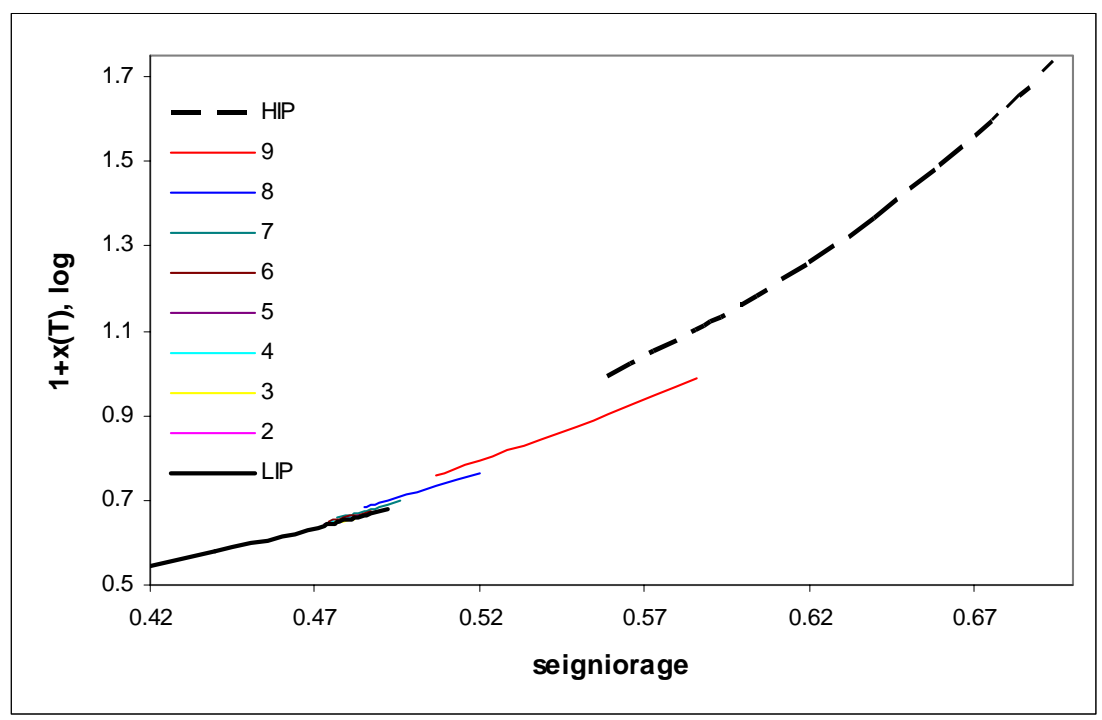

Parameter values: $\mathrm{m}_{0}=1, \theta=1.35, \beta=0.8, x^{L}=0.1, \delta=0.6, \gamma=0.15, T=10$. Computed (extreme) threshold seigniorage-values: $\alpha^{N}=0.492$ and $\alpha^{I}=0.552$. Legend as in figure 2 .

Figure 7: Dynamic Laffer-curve without coexisting extreme paths

sequence are possible equilibrium outcomes. Also, a path along which the households coordinate their actions to invest in credit-links up to $t=8$ and to stop investing from $t=9$ on is possible (at the same time, no other $\cup$-shaped $m$-path can be an equilibrium). In the case depicted in Figures $6 \mathrm{E}$ and $6 \mathrm{~F}$, seigniorage is above $\alpha^{I}$ and it is high enough so as to preclude any path different from the $m^{I}$-sequence: the prospect of a reform does not help to prevent an all-the-way flight from money. ${ }^{25}$

Equilibrium characterization when $\alpha^{I}<\alpha^{N}$. As figures 4 and 5 make clear, when the velocity of demonetization or its degree of persistence are sufficiently low, given everything else, the necessary condition for the existence of an extreme speculative hyperinflation, $\alpha^{I}<\alpha^{N}$, is violated. The following proposition describes the type of equilibria arising when the seigniorage target takes an intermediate value.

Proposition 5 Let us assume that $\alpha^{I}<\alpha^{N}$. Then, if $\alpha \in\left(\alpha^{N}, \alpha^{I}\right)$, there is at least one equilibrium in which every household exhausts its opportunities to invest in the credit technology up to some period $t$, such that $2 \leq t \leq T-2$, and stop investing from $t+1$ on, so that the equilibrium path for $m$ exhibits $a \cup$-shape. Further, over this range of $\alpha$ 's, this class of $m$-paths are the only possible ones.

Proof. See the appendix.

\footnotetext{
${ }^{25}$ Also notice that the inflation rate along the $m^{I}$-sequence just before the reform, $x_{T}$, is in all cases below the one observed in the preceding period, so that the inflation rate sequence is not a monotonic function of time along that path. This attenuating effect is driven by the positive (negative) effect of the reform on $m_{T}\left(x_{T}\right)$. However this feature of the model can not be understood as being incompatible with the empirical evidence, as a short period of downward adjustment in the inflation rate following its peak and just before the implementation of the reformed were observed in some of the most explosive hyperinflations, as those experienced by Argentina and Germany (see figure 1).
} 
This is a natural result. As an intermediate $\alpha$ rules out both extreme paths, the equilibrium time pattern of $m$ must account for the fact that the reform leads to a regime in which the value of a credit-link falls. As the households anticipate this, the reform must exert a positive impact on $m$ even before its implementation.

Figure 7 depicts a situation in which $\delta$ and $x^{L}$, while positive, are so low that $\alpha^{N}<\alpha^{I}$. We can see that the effect of seigniorage on the optimal portfolio decision and the resulting inflation sequence exhibits a high degree of smoothness, very much as the suggested by the conventional arguments based on the upward sloped arm in a steady state inflation-tax Laffer curve (see e.g. Eckstein and Leiderman 1992), in the sense that high volumes of seigniorage tend to uniformly cause high inflation.

\section{Endogenous reforms}

Although the discussion up to here has referred to the case in which the government commits to implement a fiscal-monetary reform at some time $T$ regardless of the history of the economy up to that date, most of the previous key results regarding the (in)effectiveness of an anticipated reform can be easily extended to account for the possibility that the government will only react if things get sufficiently bad, say, if the inflation rate threatens to go beyond some limits. This is the assumption followed by Obstfeld and Rogoff (1983), Nicolini (1996) and Marcet and Nicolini (2003). All these papers consider a simple rule followed by the government for deciding whether to reform or not: to implement a real-backing mechanism at some date $t$ if, absent the threat of such a reform, the inflation rate could violate some finite threshold value, $\bar{x}$ (reaction point). ${ }^{26}$ In this section I consider a similar rule, as stated below.

Assumption 4 (Reform rule). The government implements the reform at time $T^{*}+1$ if and only if, for given $m_{T^{*}-1}$, the following inequality holds

$$
\frac{m_{T^{*}-1}}{(1-\gamma)\left[1-\delta\left(1-m_{T^{*}-1}\right)\right]-\alpha} \geq \bar{x}
$$

The left hand side of this inequality is the highest inflation rate that could be observed absent the threat of the reform, which clearly corresponds to the lowest possible value of $m_{T^{*}}$, i.e. $(1-\gamma)\left[1-\delta\left(1-m_{T^{*}-1}\right)\right]$. It is helpful to rewrite (31) in the form of an upper bound for $m_{T^{*}-1}$,

$$
m_{T^{*}-1} \leq \underline{m}
$$

where $\underline{m}$ is a function of the parameters $\gamma, \delta, \alpha$ and $\bar{x} \cdot{ }^{27}$

As the interest here is to analyze the effects of a commitment to reform on the occurrence of purely expectations-driven hyperinflations, the natural context to frame this question is one in which there is a feasible non-hyperinflationary path that is consistent with the fiscal-dominance regime being implemented

\footnotetext{
${ }^{26}$ Yet, they differ in the particular real-backing mechanism at work. While Obstfeld and Rogoff (1983) assume that the government reacts by offering the possibility of redeeming money giving some productive capital in exchange, in Nicolini (1996) and Marcet and Nicolini (2003) it is assumed that the government operates a fixed-exchange rate to end the crisis.

${ }^{27} \mathrm{I}$ assume a combination of parameters such that $m_{0}>\underline{m}$. This rules out the trivial case in which the reform is automatically implemented in the first period.
} 
forever. As in the previous section, I choose the $\widetilde{m}^{N}$-sequence as the benchmark non-hyperinflationary case, as embedded in the following assumption

Assumption 5 (Existence of a status quo equilibrium). An equilibrium containing the $\widetilde{m}^{N}$ sequence is possible, i.e.

$$
\sum_{s=1}^{\infty} \beta^{s} \delta^{s-1} \frac{1-\delta^{s}\left(1-m_{0}\right)}{1-\delta^{s+1}\left(1-m_{0}\right)-\alpha} \leq \theta
$$

The left side of this inequality is $\Psi_{1}^{N}$ accordingly computed over an infinite horizon. Notice that this is the relevant measure of the long-run sustainability of this type of equilibrium since, as discussed before, $\Psi_{t}^{N}$ decays over time.

Symmetrically, the following assumption rules out the uninteresting case in which $\bar{x}$ and $\alpha$ are set in such a way that reform can never be implemented

Assumption 6 (Bounded reaction point). If $\alpha<\frac{(1-\delta)(1-\gamma)}{1-\delta(1-\gamma)}$, then the reaction point $\bar{x}$ is bounded above by

$$
\bar{x}<\left[1-\frac{(1-\delta)(1-\gamma)}{1-\delta(1-\gamma)} \alpha\right]^{-1}
$$

The right side in this inequality is the (limiting) constant inflation rate attained when the degree of monetization is at its minimum possible value, i.e. the stationary state with zero net flow of new credit links, and, hence, the highest possible inflation rate under assumption 3. Thus, this inequality rules out the possibility that the reaction point $\bar{x}$ is set at a sufficiently high level so as to always preclude the implementation of the reform. Notice that this assumption is only relevant if $\alpha$ is low enough to be maintained in the stationary state in which $m$ reaches its minimum possible value, $\frac{(1-\delta)(1-\gamma)}{1-\delta(1-\gamma)}$. If, on the contrary, $\alpha>\frac{(1-\delta)(1-\gamma)}{1-\delta(1-\gamma)}$, then a path along which the households monotonically decrease the use of money would eventually force the government to abandon its target $\alpha$, implementing a reform. ${ }^{28}$

Now, in deriving a necessary and sufficient condition for the feasibility of an extreme speculative hyperinflation similar to (23), we must take into account that the time of the eventual reform is determined endogenously. Apart from this observation, the problem is similar in its basic aspects to the case with exogenous $T$. I collect the main insights of this case in the following proposition.

Proposition 6 An extreme speculative hyperinflation is impossible and the reform is never executed if (i) $x^{L}<0$, or (ii) the reaction point $\bar{x}$ is sufficiently low. Otherwise, an extreme speculative hyperinflation that triggers the reform is possible. ${ }^{29}$

\footnotetext{
${ }^{28}$ This illustrates an interesting feature of this model. For some parameters, we can find a non-empty set of $\alpha$ 's for which the status quo equilibrium is a possible equilibrium while the sequence $\widetilde{m}^{I}$ necessarily triggers a reform since, otherwise, the seigniorage-target at some point becomes unsustainable, which in turn means that inflation can reach arbitrarily high values just before the change of regime. Such a set is $\left[\alpha^{N}, \frac{(1-\delta)(1-\gamma)}{1-\delta(1-\gamma)}\right]$. This makes the model compatible with the idea that hyperinflations are better understood as being inherently unstable processes along which inflation explodes without bound at an ever increasing rate.

${ }^{29} \mathrm{I}$ do not consider here the case with $\delta=0$, since it implies that inflation can not rise over time under this limit case, as shown in proposition 3. Nevertheless, it seems clear that in a richer environment in which, e.g. $\gamma$ varies over time in a way that inflation may potentially rise, the prospect of a reform would work here again (with $\delta=0)$ as an effective device to rule out a hyperinflationary path that would eventually unchain the reform.
} 
Proof. (i) The proof follows closely that of proposition 2. Suppose that the government implements the reform at $T^{*}$. Thus,

$$
m_{T^{*}-1} \leq \underline{m}<m_{T^{*}-2}
$$

Then, as $x_{T^{*}+1}=x^{L}<0$, the households optimally set $\phi_{s}=\lambda_{s}=0$ for $s \geq T^{*}$. The value function $\Psi$ evaluated at $T^{*}-1$ would be $\Psi_{T^{*}-1}=\beta x_{T^{*}}$, where $x_{T^{*}}=\frac{m_{T^{*}-1}}{1-\alpha}-1$. Clearly, $x_{T^{*}}<\frac{m_{T^{*}-1}^{N}}{m_{T^{*}}^{N}-\alpha}-1$, which implies that $\Psi_{T^{*}-1}<\Psi_{T^{*}-1}^{N} \leq \theta$, where the last inequality follows from assumption 5. However, as $\Psi_{T^{*}-1}<\theta$, we learn that there is no $m_{T^{*}-2}$ such that $m_{T^{*}-2}>m_{T^{*}-1}$, which contradicts (35). Thus, if $x^{L}<0$, then $m_{t}>\underline{m}$ for any $t \geq 1$, and the reform is never implemented.

(ii) In deriving the counterpart of (23), it is helpful to consider the following two steps. First, compute the inflation rate sequence, $x_{t}^{I}$, from $t=2$ up to the first date at which the threshold $\bar{x}$ could be reached in the absence of a reform, $T^{*}$. The unique solution for $T^{*}$ is implicitly given by the following correspondence

$$
\frac{m_{T^{*}-2}^{I}}{m_{T^{*}-1}^{I}-\alpha}-1<\bar{x} \leq \frac{m_{T^{*}-1}^{I}}{m_{T^{*}}^{I}-\alpha}-1
$$

Second, use $T^{*}$ to compute the sign of $\underline{\Psi}^{I}-\theta \cdot{ }^{30}$ If it is positive, then a speculative hyperinflationary path that is ended by the reform is possible. Since $\underline{\Psi}^{I}$ increases with $T^{*}$, and $T^{*}$ increases (discretely) with $\bar{x}$, we learn that there is a minimum $\bar{x}$ such that an extreme speculative hyperinflation is only possible for values of $\bar{x}$ above that lower bound.

The intuition behind these results is simple. A credible commitment by the government to switch from a fiscal-dominance to an orthodox monetary-dominance one when the inflation rate threatens to reach a sufficiently high value will only prevent a speculative hyperinflation and, hence, the regime switch will not take place in equilibrium, if the public understands that the government will not let the inflation rate to reach very high values before intervening or if it is able to implement a sufficiently restrictive monetary policy so that the economy jumps to the full-level of monetization at the time of the reform, as explained in proposition 2. Yet, as emphasized in section 2, these two conditions are widely violated in real hyperinflationary episodes.

Figure 8 depicts three alternative scenarios. In the first one, with $x^{L}>0$, the threshold $\bar{x}$ is set at a sufficiently low level, $x^{a}$, so that the reform is never implemented, i.e. $\underline{\Psi}^{I}\left(x^{a}\right)<\theta$. In the second one, maintaining $x^{L}>0$, the government is assumed to react only when inflation is sufficiently high, $x^{b}$ $\left(x^{b}>x^{a}\right)$ so that the eventual reform is effective in stopping the hyperinflation but not in preventing it, i.e. $\underline{\Psi}^{I}\left(x^{b}\right)>\theta$. In the last one, the government commits to a negative post-reform rate, $x^{L}<0$, so that regardless the particular $\bar{x}\left(x^{c}\right.$ in the figure), the reform is never implemented.

\footnotetext{
${ }^{30}$ Where now $\underline{\Psi}^{I}$ is understood as the lowest element of the sequence $\left\{\Psi_{t}^{I}\right\}_{t=1}^{T^{*}-1}$.
} 


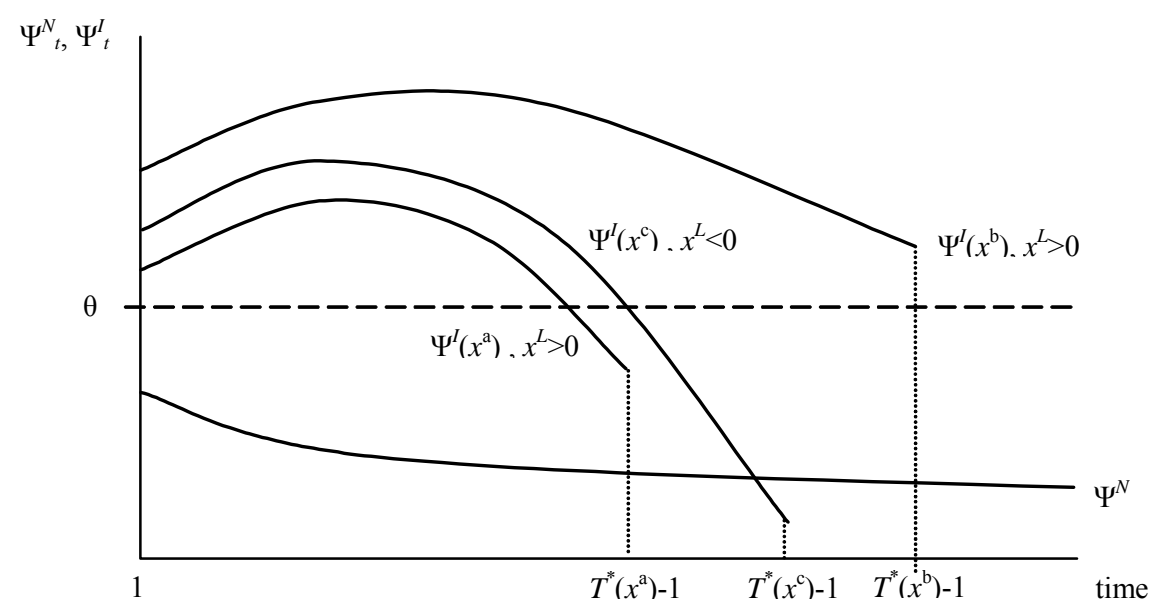

Figure 8: Endogenous reforms: alternative scenarios

\section{Concluding remarks}

The model presented in this paper aims to reconcile several long-standing views on the causes and dynamics of extreme hyperinflationary processes with the objective of providing a simple theoretical explanation of the main stylized facts observed during those episodes.

A central theme in the paper is how to make three of the most influential stories in the literature compatible with each other and with the empirical facts we are after. First, a high level of fiscal pressure leading to relatively high levels of deficit monetization is usually identified as a leading cause of hyperinflations. Indeed, stopping a hyperinflation usually involves, among other things, a drastic reduction in seigniorage. Second, it is well understood that a seigniorage-based monetary rule may be compatible with a multiplicity of inflation equilibrium-paths, as this rule leaves the monetary aggregate indeterminate. Private expectations are frequently thought as of being an important mechanism behind hyperinflationary processes, an argument that seems specially compelling to account for one of the most robust stylized facts: the lack of strong correlation between seigniorage (i.e. the fiscal "fundamental") and inflation over the course of a hyperinflation. Third, for a large class of models widely studied in the previous theoretical and empirical literature (namely, models incorporating a demand for real balances à la Cagan), it is difficult to accept an explanation for a hyperinflation based on rational self-fulfilled prophecies, for the government commitment to eventually implement a regime-reform, abandoning the fiscal-dominance regime, and to back its currency with taxes implies, first, that rational speculative paths are not possible, as shown by Obstfeld and Rogoff (1983), and, second, that higher volumes of seigniorage over that regime would be associated with more severe disinflationary processes.

The mutual incompatibility of the above arguments with the hypothesis of rational expectations and with the empirical evidence is not a new result. The solutions given to this problem in the previous literature vary to a great extent. In some cases the rational expectations assumption is abandoned (e.g. Marcet and Nicolini 2003, and Sargent et al. 2005) while in others the possibility of a fiscal-monetary 
reform is left out of the picture (e.g. Bruno and Fischer 1990) or, even, the anticipation of such a reform is blamed for being the cause of a hyperinflation (e.g. Bental and Eckstein 1990, and Paal 2000). The approach taken in this paper follows a different route

Based on some previous works on dynamic processes of financial innovation, I study how the persistence in the use of alternative means of transactions affects the effectiveness of an equilibrium selection device similar to the one studied by Obstfeld and Rogoff. This is a natural question in this context, for the experience of those countries which suffered extreme hyperinflations reveals a high degree of hysteresis in the demand for real money. Using a simple cash-and-credit model that allows for persistence in the usage of credit, it is argued that the robustness, and the rather extreme implications, of an argument $\grave{a}$ la Obstfeld and Rogoff's follow directly from the assumption of instantaneous adjustment in the private demand for real money (i.e. no room for hysteresis). Once this assumption is relaxed, the effectiveness of the prospect of a future orthodox reform for ruling out speculative hyperinflationary paths is an endogenous outcome. In particular, whether the government's commitment to reform exerts any anti-inflationary effect before the time of its implementation, hinges on a wide array of structural factors and policy choices. For example, a high volume of seigniorage collected over the pre-reform period, a long period of government inactivity and a weak fiscal position after the reform are likely to set down the necessary conditions for a hyperinflation. When, in addition, individuals do not face important barriers to access to the credit-technology and the effects of the investments in this technology extend over a longer horizon, an extreme speculative hyperinflation happens to be a true possibility, even if individuals rationally expect a future drastic reform.

While the model offers a theoretical basis compatible with the view of a hyperinflation as a bubble phenomenon, it also provides some useful guidance in identifying the economic-policy conditions that may lead to such a painful experience, for the conditions under which such paths are possible are not arbitrary, as in some of the previous literature. Namely, only countries that, for some reason, are advocated to rely on seigniorage in a significant amount and/or for a sufficiently prolonged period are likely to put themselves on the knife-edge. On the theoretical side, the model offers a simple resolution to the incompatibility problem among the three popular approaches aforementioned in a way that renders it a useful tool to understand the empirical evidence, and it does so by including an ingredient which can hardly be labelled as unrealistic or empirically irrelevant: the existence of hysteresis in the degree of monetization following the end of the hyperinflation. 


\section{Appendix}

\section{Proof of Proposition 5.}

Let us define $\widetilde{\Psi}_{t}$ as the time $t$ shadow-value function associated with the following $m$-sequence

$$
m_{s}=\left\{\begin{array}{cc}
(1-\gamma)\left[1-\delta\left(1-m_{s-1}\right)\right] & \text { for } s=2, \ldots, t-1 \\
1-\delta\left(1-m_{s-1}\right) & \text { for } s=t, \ldots, \infty
\end{array}\right.
$$

It can be readily verified that (18) is sufficient for $\widetilde{\Psi}_{t}$ to be bounded by $\Psi_{t}^{N}$ and $\Psi_{t}^{I}$, i.e. $\Psi_{t}^{N}<\widetilde{\Psi}_{t}<\Psi_{t}^{I}$, for $t=2, \ldots, T-1$. To see this notice that for any $t$ within this interval, $\widetilde{\Psi}_{t}$ and $\Psi_{t}^{N}$ look similarly, as both functions are defined under the assumption that no household is investing in the credit technology from date (inclusive) on. However, as $m_{t-1}$ under $\widetilde{\Psi}_{t}$ is lower than under $\Psi_{t}^{N}$, (18) implies that every element in the equilibrium inflation sequence $\left\{x_{s}\right\}_{s=t+1}^{T}$ is higher for $\widetilde{\Psi}_{t}$. When comparing $\widetilde{\Psi}_{t}$ and $\Psi_{t}^{I}$, notice that $m_{t-1}$ is common for both functions, but $m_{s}$ for $s \geq t$ is lower under $\Psi_{t}^{I}$, so the corresponding equilibrium inflation sequence $\left\{x_{s}\right\}_{s=t+1}^{T}$ is higher for $\Psi_{t}^{I}$ than for $\widetilde{\Psi}_{t}$ and, hence, $\widetilde{\Psi}_{t}<\Psi_{t}^{I}$.

Let us first consider the case in which $\widetilde{\Psi}_{2} \leq \theta$. As $\alpha \in\left(\alpha^{N}, \alpha^{I}\right)$, we learn that $\Psi_{1}^{I}>\Psi_{1}^{N}>\theta$ must hold, where the first inequality follows from (18) and the second one holds by construction. Consider a $m$-path such that $m_{t}=1-\delta\left(1-m_{t-1}\right)$ for $t \geq 2$. Clearly such a path is an equilibrium one. First, $\widetilde{\Psi}_{2} \leq \theta$ implies, by definition, that having invested in the credit technology at $t=1$,no investing from period 2 on is optimal. Second, the actual shadow-value function at $t=1$ conditional on investing in that period and no investing from that period on, $\Psi_{1}$, must satisfy $\Psi_{1}^{I}>\Psi_{1}>\Psi_{1}^{N}>\theta$, so it is indeed optimal to invest in the first period. Then, consider the case in which $\widetilde{\Psi}_{2}>\theta$, so that $\Psi_{2}^{I}>\theta$, as well. As $\underline{\Psi}_{t}^{I}<\theta$, there must exist, at least, one date $t_{1} \geq 3$ such that $\Psi_{t_{1}=1}^{I} \geq \theta>\Psi_{t_{1}}^{I}$. Let us denote the lowest possible $t_{1}$ as $t_{1}^{\min }$. As $\widetilde{\Psi}_{t}<\Psi_{t}^{I}$, there exists also, at least, one date $t_{2}$, with $3 \leq t_{2} \leq t_{1}^{\min }$, such that $\Psi_{t_{1}=1}^{I} \geq \theta>\Psi_{t_{1}}^{I}$. Let us denote the lowest possible $t_{2}$ as $t_{2}^{\min }$. Then, by looking forward, not investing from period $t_{2}^{\min }$ on is optimal, conditional on having invested in every period $t=1, \ldots, t_{2}^{\min }-1$. Looking backwards, as $\widetilde{\Psi}_{t}>\theta$ for $t=1, \ldots, t_{2}^{\min }-1$, we learn that the actual $\Psi_{t}$ satisfies $\Psi_{t}>\widetilde{\Psi}_{t}>\theta$ for $t=1, \ldots, t_{2}^{\min }-1$, so it is optimal to invest over that interval when it is anticipated that no new investments will be made from $t_{2}^{\min }$ on. Thus, there is always, at least, one equilibrium path for any $\alpha \in\left(\alpha^{N}, \alpha^{I}\right)$ along which the time-path of $m$ has a $\cup$-shape and, hence, the equilibrium inflation path depicts a $\cap$-shape over the pre-reform period.

Also, notice that if $\alpha^{I}>\alpha^{N}$ holds, then there can not exist any equilibrium with a $\cap$-shaped path for $m$ over the pre-reform period, i.e. situations in which the households coordinate to give up every opportunity for investing in the credit technology up to some date between 2 and $T-1$ and to invest from that particular date on. To see this, notice that a necessary condition for not investing in the first period is that $\Psi_{1}^{N} \leq \theta$, and, hence, an equilibrium $\cap$-shaped path for $m$ requires $\alpha \leq \alpha^{N}$. Also, for investing from some date $\widehat{t}$ on, such that $2 \leq \widehat{t} \leq T-1$, not having invested over the period running from 1 to $\widehat{t}-1$, the following condition must hold

$$
\widehat{\Psi}_{t} \equiv \sum_{s=1}^{T-t} \beta^{s} \delta^{s-1} \widehat{x}_{t+s}+\frac{\beta^{T-t+1} \delta^{T-t}}{1-\beta \delta} x^{L} \geq \theta, \quad \forall t=\widehat{t}, \ldots, T-1
$$

where

$$
\widehat{x}_{t+s}=\frac{(1-\delta)(1-\gamma) \frac{1-[\delta(1-\gamma)]^{s-1}}{1-\delta(1-\gamma)}+[\delta(1-\gamma)]^{s-1} m_{\widehat{t}}}{(1-\delta)(1-\gamma) \frac{1-[\delta(1-\gamma)]^{s}}{1-\delta(1-\gamma)}+[\delta(1-\gamma)]^{s} m_{\widehat{t}}-\alpha},
$$

where $s=1, \ldots, T-\widehat{t}$ for some $\widehat{t}=2, \ldots, T-1$

and $m_{\widehat{t}}=1-\delta^{\widehat{t}}\left(1-m_{0}\right)$ 
Exploiting the fact that the shadow-value functions at any date $t$ are inversely related to $m_{t}$, regardless of the evolution of $m$ from that date on, we learn that

$$
\Psi_{t}^{I}>\widehat{\Psi}_{t}, \quad \forall t=\widehat{t}, \ldots, T-1
$$

Thus, if the necessary condition for a $\cap$-shaped $m$-path (A1) holds and $\underline{\Psi}^{I}$ is located within the timeinterval $\widehat{t}, \ldots, T-1$, then it must be the case that $\underline{\Psi}^{I}>\theta$. A stronger result can be obtained for the alternative case in which $\underline{\Psi}^{I}$ is located before $\widehat{t}$, since, in this case, the positive effect of a lower $m$ on the shadow-value function is reinforced by a positive effect coming from a longer horizon over which the investment in the credit technology is expected to yield positive returns, i.e. strictly positive savings, so that the following inequality must hold

$$
\text { lowest element of }\left\{\Psi_{t}^{I}\right\}_{t=1}^{\widehat{t}-1}>\text { highest element of }\{\widehat{\Psi}\}_{t t=\widehat{t}}^{T=1} \geq \theta
$$

Therefore, regardless of the time-location of $\underline{\Psi}^{I}$, the existence of a $\cap$-shaped $m$-path requires a level of seigniorage $\alpha$, such that $\alpha^{I}<\alpha \leq \alpha^{N}$, and, as a result, when $\alpha^{I}>\alpha^{N}$ holds, the only class of nonmonotonic equilibrium $m$-paths are $\cup$-shaped, i.e., as the time of the reform comes closer, its prospect exerts a positive effect on the demand for real balances. Q.E.D.

\section{References}

[1] Adam, K., G.W. Evans, and S. Honkapojha. 2005. "Are Hyperinflation Paths Learnable?," unpublished manuscript.

[2] Albanesi, S. 2006. "Inflation and Inequality," Journal of Monetary Economics, forthcoming.

[3] Bental, B. and Z. Eckstein. 1990. "The Dynamics of Inflation with Constant Deficit under Expected Regime Change," The Economic Journal, 100 (403): 1245-1260.

[4] Blackburn, K., and M. Sola. 1996. "Market Fundamentals versus Speculative Bubbles: A New Test Applied to the German Hyperinflation," International Journal of Finance and Economics, 1 (4): 303-317.

[5] Bruno, M., and S. Fischer. 1990. "Seigniorage, Operating Rules and the High Inflation Trap," Quarterly Journal of Economics, 105 (2): 353-374.

[6] Bruno, M., S. Fischer, E. Helpman, N. Liviatan, and L. Meridor. 1991. Lessons of Economic Stabilization and Its Aftermath. The MIT Press: Cambridge (Mass.).

[7] Cagan, P. 1956. "The Monetary Dynamics of Hyperinflation," in Milton Friedman (Ed.): Studies in the Quantity Theory of Money. Chicago: University of Chicago Press.

[8] Calvo, G., and C. Végh. 1992. "Currency Substitution in Developing Countries: An Introduction," Revista de Análisis Economico, 7 (1): 3-27.

[9] Catão, L., and M. Terrones. 2005. "Fiscal Deficits and Inflation," Journal of Monetary Economics, 52: 529-544.

[10] Chang, R. 1994. "Endogenous Currency Substitution, Inflationary Finance, and Welfare," Journal of Money, Credit and Banking, 26 (4): 903-916.

[11] Dornbusch, R., F. Sturzenegger, and H. Wolf. 1990. "Extreme Inflation: Dynamics and Stabilization," Brookings Papers on Economic Activity, 2: 1-84. 
[12] Drazen, A., and Helpman, E. 1990. "Inflationary Consequences of Anticipated Macroeconomic Policies," The Review of Economic Studies, 57 (1): 147-164.

[13] Eckstein, Z., and L. Leiderman. 1992. "Seigniorage and the Welfare Cost of Inflation: Evidence from an Intertemporal Model of Money and Consumption," Journal of Monetary Economics, 29(3): $389-410$.

[14] Fischer, S., R. Sahay and C. A. Végh. 2002. "Modern Hyper- and High Inflations," Journal of Economic Literature, 40 (3): 837-880.

[15] Flood, R. P. and, P. M. Garber. 1980. "Market Fundamentals versus Price-level Bubbles: The First Tests," Journal of Political Economy 88: 745-770.

[16] Gutiérrez, M. J., and J. Vázquez. 2004. "Explosive Hyperinflation, Inflation-Tax Laffer Curve, and Modeling the Use of Money," Journal of Institutional and Theoretical Economics, 160 (2): 311-326.

[17] Holtfrerich, C. L. 1986. The German Inflation. 1914-1923. Berlin: Walter de Gruyter.

[18] Hooker, M. A. 2000. "Misspecification versus Bubbles in Hyperinflation Data: Monte Carlo and Interwar European Experience," Journal of International Money and Finance, 19: 583-600.

[19] Imrohoroglu, S. 1993. "Testing for Sunspot Equilibria in the German Hyperinflation," Journal of Economic Dynamics and Control, 17: 289-317.

[20] Ireland, P. 1995. "Endogenous Financial Innovation and the Demand for Money," Journal of Money, Credit and Banking, 27 (1): 106-123.

[21] Kamin, S. B., and N. R. Ericsson. 2003. "Dollarization in Post-Hyperinflationary Argentina," Journal of International Money and Finance, 22: 185-211.

[22] Kiguel, M. A. 1989. "Budget Deficits, Stability, and the Monetary Dynamics of Hyperinflation," Journal of Money, Credit and Banking, 21 (2): 148-157.

[23] Kiguel, M. A., and P. A. Neumeyer. 1995. "Seigniorage and Inflation: The Case of Argentina," Journal of Money, Credit and Banking, 27 (3): 672-682.

[24] Leattau, M., and Van Zandt, T. 2003. "Robustness of Adaptive Expectations as an Equilibrium Selection Device," Macroeconomic Dynamics, 7: 89-118.

[25] Loyo, E. 2001. "Tight Money Paradox on the Loose: A Fiscalist Hyperinflation," mimeo, JFK School of Government, Harvard University.

[26] Lucas, R. E. and N. L. Stokey. 1987. "Money and Interest in a Cash-in-Advance Economy," Econometrica, 55: 491-513.

[27] Marcet, A., and Nicolini, J. P. 2003. "Recurrent Hyperinflations and Learning," American Economic Review, 93 (5): 1476-1498.

[28] Mondino, G., Sturzenegger, F., and Tommasi, M. 1996. "Recurrent High Inflation and Stabilization: A Dynamic Game," International Economic Review, 37 (4): 981-996.

[29] Nichols, D. A. 1974. "Some Principles of Inflationary Finance," Journal of Political Economy, 82 (2, part 1): 423-430.

[30] Nicolini, J. P. 1996. "Ruling Out Speculative Hyperinflations. The Role of the Government," Journal of Economic Dynamics and Control, 20: 791-809. 
[31] Obstfeld, M., and Rogoff, K. 1983. "Speculative Hyperinflations in Maximizing Models: Can We Rule Them Out?," Journal of Political Economy, 91 (4): 675-687.

[32] Paal, B. 2000. "Destabilizing Effects of a Successful Stabilization: A Forward-Looking Explanation of the Second Hungarian Hyperinflation," Economic Theory, 15: 599-630.

[33] Petrovic, P., Z. Bogetic, and Z. Vujosevic 1999. "The Yugoslav Hyperinflation of 1992-1994: Causes, Dynamics and Money Supply Process," Journal of Comparative Economics, 27: 335-353.

[34] Reinhart, C. M., K. S. Rogoff and M. A. Savastano. 2003. "Addicted to Dollars," NBER Working Paper no. 10015.

[35] Reinhart, C. M. and M. A. Savastano. 2003. "The Realities of Modern Hyperinflations," IMF, Financial and Development (June): 20-23.

[36] Romer, D. 2001. Advanced Macroeconomics. New York: McGraw Hill.

[37] Sachs, J. 1987. "The Bolivian Hyperinflation and Stabilization," American Economic Review, P\&্P, 77 (2): 279-283.

[38] Sachs, J. 1995. "Do We Need an International Lender of Last Resort," Frank D. Graham Lecture, Princeton University (April 20).

[39] Sargent, T. J. 1986. Rational Expectations and Inflation. New York: Harper\&Row Publishers.

[40] Sargent, T. J., and N. Wallace. 1981. "Some Unpleasant Monetarist Arithmetic," Federal Reserve Bank of Minneapolis Quarterly Review, Fall..

[41] Sargent, T. J. and N. Wallace. 1975. "Rational' Expectations, the Optimal Monetary Instrument, and the Optimal Money Supply Rule," Journal of Political Economy, 83: 241-254.

[42] Sargent, T. J., and N. Wallace. 1987. "Inflation and the Government Budget Constraint," in A. Razin and E. Sadka (Eds.), Economic Policy in Theory and Practice. London: Macmillan Press.

[43] Sargent, T. J., N. Williams, and T. Zha. 2005. "Fiscal Determination of Hyperinflation," unpublished manuscript.

[44] Uribe, M. 1997. "Hysteresis in a Simple Model of Currency Substitution," Journal of Monetary Economics, 40: 185-202. 